\title{
Calibration of regional groundwater flow models: Working toward a better understanding of site-specific systems
}

\author{
Maria Clara Castro \\ Department of Geological Sciences, University of Michigan, Ann Arbor, Michigan, USA \\ Patrick Goblet \\ Centre d'Informatique Géologique, Ecole des Mines de Paris, Fontainebleau, France
}

Received 14 August 2002; accepted 19 March 2003; published 28 June 2003.

[1] This work highlights the lack of unique solutions for regional groundwater flow models and quantifies the degree of freedom concerning hydraulic conductivities for models calibrated on measured hydraulic heads. The potential of ${ }^{4} \mathrm{He}$ as an independent tracer at reducing the nonuniqueness problem is tested. Four different calibrated groundwater flow scenarios are presented for the Carrizo aquifer and surrounding formations in Texas. It is shown that variations of hydraulic conductivities up to 2 orders of magnitude in the Carrizo aquifer and overlying confining layer lead to similar calculated hydraulic heads. No clear-cut arguments are present to invalidate one groundwater flow scenario over a different one. In contrast, when tested with a ${ }^{4} \mathrm{He}$ transport conceptual model, all groundwater flow scenarios except one failed to reproduce a coherent ${ }^{4} \mathrm{He}$ transport behavior in the system. This study exemplifies possible future contributions of ${ }^{4} \mathrm{He}$ at discerning which model most closely replicates natural conditions. INDEX TERMS: 1829 Hydrology: Groundwater hydrology; 1832 Hydrology: Groundwater transport; 1040 Geochemistry: Isotopic composition/chemistry; KEYWORDS: helium-4, model validation, groundwater residence time

Citation: Castro, M. C., and P. Goblet, Calibration of regional groundwater flow models: Working toward a better understanding of site-specific systems, Water Resour. Res., 39(6), 1172, doi:10.1029/2002WR001653, 2003.

\section{Introduction}

[2] For 4 decades, hydrogeologists have tried to "capture" and to understand the main features of specific groundwater systems with the aid of numerical models [e.g., Toth, 1962; Bredehoeft and Pinder, 1973; Trescott, 1975; Konikow and Bredehoeft, 1978; Prickett et al., 1981; Ledoux, 1986; Goblet, 1989; Bredehoeft, 1990; Banton et al., 1997; Goblet, 1999]. Initially developed with the primary goal of improving assessment and management of groundwater resources, they have evolved in combination with solute transport models to address issues of contaminated aquifer remediation. More recently, the need to evaluate the feasibility of radioactive waste repositories in the subsurface has triggered the development of numerous inverse algorithm methods. Those were incorporated into existing or new models for the description of spatial variability of parameters such as hydraulic head and/or hydraulic conductivity [e.g., Cooley, 1983; Townley and Wilson, 1985; Carrera and Neuman, 1986a, 1986b; Sun and Yeh, 1992; Harvey and Gorelick, 1995].

[3] Although techniques and/or methods employed in different numerical models are extremely diverse, they all share a common goal, which is to predict the response of particular groundwater systems to any set of stresses that may arise. In the case of nuclear waste disposal, predictions over extremely long time periods, over tens of thousands of

Copyright 2003 by the American Geophysical Union. 0043-1397/03/2002WR001653 years, are expected to be made. However, independently of the techniques adopted, all models share a common problem: nonuniqueness of model solutions, which, in turn, compromises the accuracy of model prediction. This issue, as well as ones of calibration and validation of groundwater flow models, has been extensively described and discussed in the literature [e.g., Alley and Emery, 1986; Beven, 1989; Konikow and Bredehoeft, 1992; de Marsily et al., 1992; Maloszewski and Zuber, 1993; McLaughlin and Townley, 1996; Zimmerman et al., 1998].

[4] Typically, groundwater flow models are calibrated based on measured hydraulic head and/or hydraulic conductivity values. Nevertheless, as pointed out by Konikow and Bredehoeft [1992], a good match does not prove the validity of the model because the nonuniqueness of model solution means that a good comparison can be achieved with an inadequate or erroneous model. Zimmerman et al. [1998] point out that many different transmissivity fields may yield equally good fits to available measurements, though some of those fits maybe fortuitously closer to the "true" transmissivity field than others, even though all are equally consistent with the data presented. This general lack of uniqueness stems, among others, from our difficulty to properly and fully describe the internal properties and boundary conditions of a groundwater system. More often than not, our knowledge of all necessary parameters to be described is insufficient so that we end up with a higher number of unknowns as compared to the number of equations to be solved (see discussion by Maloszewski and Zuber [1993] and others). In view of the situation described, i.e., limited 
predictive accuracy due to absence of uniqueness, one could think that the usefulness of numerical models to represent groundwater flow systems is quite limited. This is, however, not the case. Konikow and Bredehoeft [1992] conclude that models cannot be validated, only invalidated. These authors state that because one cannot validate models, this forces one to perform a critical set of experiments in an attempt to test or invalidate our model (or hypothesis). They state (p. 82), "Our understanding only increases when we falsify a hypothesis (model) and advance to a new, more encompassing hypothesis (model)." As such, every time we invalidate a model, we acquire an increased understanding of the hydrogeological system being studied.

[5] Our interest in reproducing the groundwater flow regime of particular systems is quite the opposite to that of most hydrogeologists: We do not attempt to predict the response of models to particular stresses; instead, we attempt to reproduce groundwater flow systems of the past. So that we remain humble in the goals to be attained, we would be satisfied, as a first step, at making sure that one can actually reproduce the groundwater flow system as it is taking place at present time or, more specifically yet, at present time before artificial stresses were induced into the system. This less common need to reproduce past groundwater flow regimes is emphasized by recent efforts to reconstruct past climates through atmospheric paleotemperatures estimated through noble gases, commonly referred to as NGT (noble gas temperatures). As discussed by Castro et al. [2000], the establishment of chronologies for climate and environmental records archived in groundwater flow systems has been strongly limited by the period accessible to ${ }^{14} \mathrm{C}$ dating (35,000-40,000 years). In order to establish a direct correspondence between NGTs and a particular groundwater age, one has to ensure a well-developed understanding of the groundwater flow system in question. That is, like all other modelers, we are faced with the dilemma of whether or not our calibrated model is indeed representative of the real system we are trying to reproduce [e.g., Maloszewski and Zuber, 1993].

[6] In this contribution, through calibration of a regional groundwater flow model in a complex system, statements made by Konikow and Bredehoeft [1992], Maloszewski and Zuber [1993], and others will be highlighted. A number of possible scenarios (multiple solutions) for calibrated models on hydraulic heads will be presented for the Carrizo aquifer in Texas, and evidence will be shown for the high degree of freedom available to achieve such calibrations. It will be shown that no particular feature is present to indicate which of the possible calibration scenarios is actually closer to the "true" model. Subsequently, assuming the behavior of ${ }^{4} \mathrm{He}$ to be reasonably well known in this particular system [see Castro et al., 2000], an attempt at calibrating the distribution of ${ }^{4} \mathrm{He}$ concentrations in the Carrizo aquifer is presented. Through a sensitivity analysis, it will be shown that attempts failed for all the presented groundwater flow model calibration scenarios, except for one. It is our conviction that the use of an independent tracer such as ${ }^{4} \mathrm{He}$ contributes to an increased confidence in groundwater flow model results by strongly reducing the number of solutions available, at least for regional groundwater systems where a limited number of measured physical parameters such as hydraulic head is available. This contribution will also have shown the constraints imposed by ${ }^{4} \mathrm{He}$ on upward leakage occurring in neighboring aquitards, an issue that is not always obvious to decipher (see, for example, discussion by Bredehoeft et al. [1983]).

\section{Geological and Hydrogeological Setting of the Carrizo Aquifer and Surrounding Formations}

[7] The Carrizo aquifer, a major groundwater flow system, is part of a thick regressive sequence of terrigenous clastics that formed within fluvial, deltaic, and marine depositional systems in the Rio Grande Embayment area of South Texas on the northwestern margin of the Gulf Coast Basin (Figure 1a). Because of the abundant fresh water it contains and subsequent discovery of oil and gas fields in the region, this sequence has been extensively investigated by the U.S. Geological Survey, the Texas Water Commission, the Bureau of Economic Geology and others [e.g., Mason, 1960; Alexander and White, 1966; Pearson and White, 1967; Fisher, 1972; Marquardt and Rodriguez, 1977; Fogg et al., 1983].

[8] In Atascosa and McMullen counties, the area of the present study, the Carrizo aquifer is a confined, massive, medium-grained sandstone of Eocene age (Figures 1a and 1b). Although Plummer [1932] and others placed this formation as being part of the Claiborne Group, the Carrizo aquifer belongs, in fact, to the Wilcox Group and, more specifically, comprises the uppermost part of the upperWilcox [see Murray, 1955; Fisher, 1969; Bebout et al., 1978]. The facies sequence of the upper-Wilcox and Carrizo aquifer was formed by a wave-dominated, highly destructive delta system and the associated fluvial and marine systems. The sandstones of the Carrizo aquifer, dominant in the northern part of the study area, lie unconformably on the lower part of the upper-Wilcox (Figure 1c) to evolve gradually, in the downdip direction, into the later, with an observed increase in shales and mudstones. The LowerWilcox Formation, the oldest formation of Tertiary age, was formed primarily by a highly constructive deltaic system and is characterized by thick, laminated, and organically rich mudstone layers. These are interbedded with thin layers of laminated argillaceous sand and arenaceous shale and with layers of massive clay. The lower part of the Upper-Wilcox Formation together with the Lower-Wilcox, display a thickness over $600 \mathrm{~m}$ in proximity to the outcrop areas, and reach thickness over $2400 \mathrm{~m}$ at depths greater than $3000 \mathrm{~m}$.

[9] The Recklaw Formation, a confining layer primarily composed of shale, fine sand, and marine mudstones, conformably overlies the Carrizo aquifer. This formation is overlain by the Queen City aquifer. The Queen City was formed as a highly destructive, wave-dominated deltaic system and is characterized by well-developed, thick coastal barrier sands in both counties, making it a rather productive aquifer in the area. These two formations are part of the Claiborne Group.

[10] These formations outcrop for the most part in the study area, in the northern part of Atascosa County (see Figure 1b). Together with the upper formations of the Claiborne Group, they outcrop subparallel to the presentday coastline along a southwest-northeast wide band across Texas (Figure 1a), dipping toward the southeast. The Carrizo aquifer terminates into a major $32 \mathrm{~km}$ wide growth-fault system (Figure 1b) commonly known as the Wilcox Geo- 


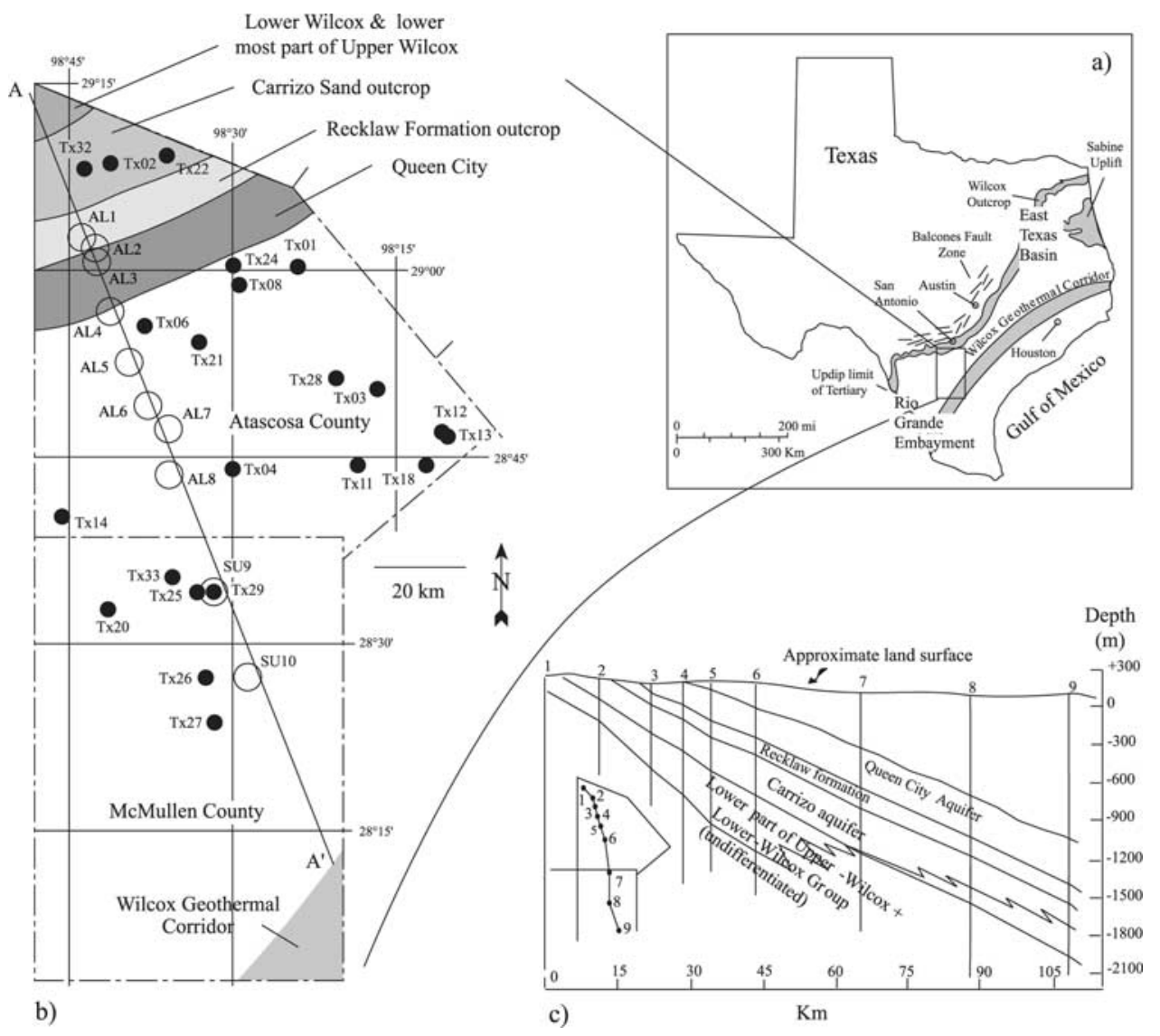

Figure 1. Simplified diagram of the studied area and formations in southwestern Texas. (a) Geographical and tectonic context of the area of investigation within Texas (adapted from Bebout et al. [1978] and Hamlin [1988]). (b) Detailed area of investigation. Latitude and longitude are indicated, as well as the location of cross section A- $\mathrm{A}^{\prime}$, in which simulations of groundwater flow and mass transport were carried out; the location of all ${ }^{4} \mathrm{He}$ sampled sites in Atascosa and McMullen Counties [cf. Castro et al., 2000] are also indicated as well as that of the wells for which hydraulic head measurements are used for calibration of the groundwater flow model, solid and open circles, respectively. (c) General schematic representation of cross section in the area for the four studied formations: the Lower-Wilcox and lower part of the UpperWilcox formations undifferentiated, the Carrizo Aquifer, the Recklaw Formation, and the Queen City aquifer.

thermal Corridor [Bebout et al., 1978]. At the top of this geopressured zone, groundwater temperatures reach over $150^{\circ} \mathrm{C}$. These growth-faults define an abrupt increase in thickness and dip of the Wilcox Group, where thick sections of sand and mud were deposited. Strong subsidence along these faults resulted in the isolation of these units and prevented lateral escape of pore fluids during subsequent compaction. Faults of smaller importance are also found in Atascosa and McMullen counties.

[11] A paucity of information on the groundwater flow system within the Recklaw and Queen City formations is available. For the Carrizo aquifer, rainfall generally recharges the aquifer in the outcrop areas and groundwater flows toward the southeast. Discharge occurs by crossformational upward leakage driven by high fluid pressure, and along fault-related permeability pathways [Hamlin, 1988]. Regionally, the Carrizo aquifer has a highly variable thickness, reaching $250 \mathrm{~m}$ in the central part of the study area, decreasing to around $50 \mathrm{~m}$ in the southern part of McMullen County. The Carrizo sand is dominated by freshwater, but salinity increases toward the southeast, reaching values of up to $10 \mathrm{~g} \mathrm{~L}^{-1}$ in the southern part of McMullen county [Alexander and White, 1966; Harris, 1965; Payne, 1975].

\section{Governing Equations and Modeling Tool}

[12] To model the groundwater flow and mass transport of ${ }^{4} \mathrm{He}$ in the Carrizo aquifer, two main classical equations are solved. For incompressible fluids, the water flow equation is expressed as a function of hydraulic head. For a twodimensional problem, this equation can be given as

$$
\frac{\partial}{\partial x}\left(K x x \frac{\partial h}{\partial x}\right)+\frac{\partial}{\partial z}\left(K z z \frac{\partial h}{\partial z}\right)=S_{s} \frac{\partial h}{\partial t}+q
$$

where $K x x$ and $K z z$ represent the hydraulic conductivity ( $\mathrm{L} \mathrm{T}^{-1}$ ) in the $x$ and $z$ directions, taken to be the main directions of anisotropy, $h$ represents the hydraulic head (L), $S_{s}$ is the specific storage $\left(\mathrm{L}^{-1}\right)$, and $q$ is a source term $\left(\mathrm{T}^{-1}\right)$ representing the amount of fluid withdrawn or added (if negative) per unit volume of porous medium. In this 


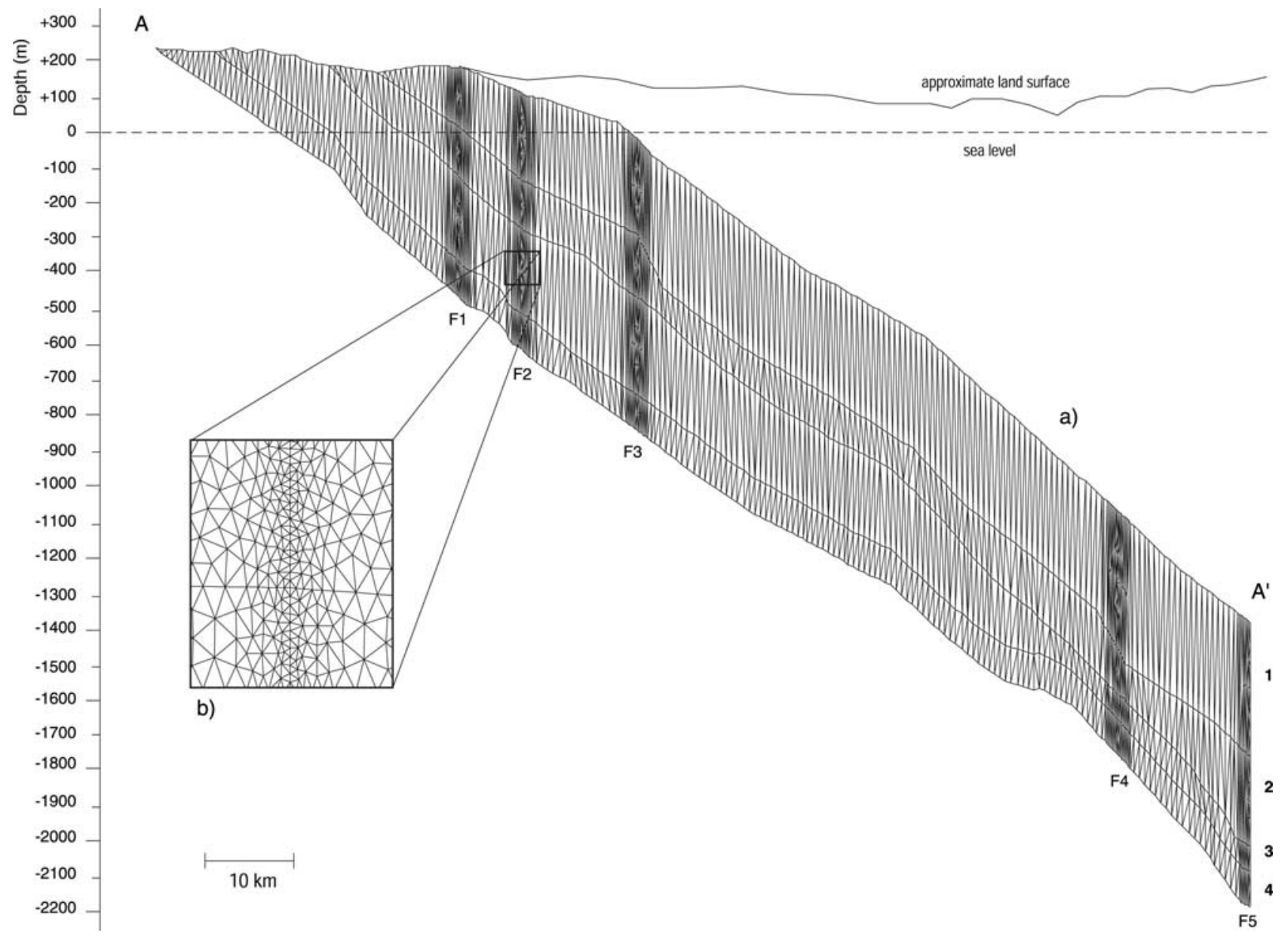

Figure 2. Simplified diagram of the mesh representing the Carrizo aquifer and surrounding formations. (a) The density of the mesh here presented is 24 times inferior to that one used in the simulations (1, Queen City Aquifer; 2, Recklaw formation; 3, Carrizo Aquifer; 4, lower part of the Upper-Wilcox and Lower-Wilcox formations undifferentiated). The location of intercepted faults by the cross section is indicated, respectively, F1, F2, F3, F4, and F5. The approximate land surface topography as well as the sea level location are also indicated. (b) Triangulation detail of the real mesh at the vicinity of fault F2.

contribution, because the Carrizo and Queen City aquifers are for most of the studied area freshwater reservoirs, and because gravity is the main force driving water movement [see Alexander and White, 1966], density variations are considered to be negligible. A detailed evaluation of the density effects will be presented in a later contribution. Taking into account the information available, the water flow was assumed to be in steady state.

[13] With respect to the equation of mass transport for ${ }^{4} \mathrm{He}$ isotopes we will be mostly concerned with three transport processes: advection, dispersion, and molecular diffusion. Thus these three mechanisms will be accounted for and the transport equation will be expressed as

$$
\operatorname{div}[(\omega d+\bar{\alpha}|U|) \operatorname{grad} C-\vec{U} C]=\omega \frac{\partial C}{\partial t}+q m
$$

where $\omega$ is the porosity, $d$ is the diffusion coefficient in porous media (diffusion coefficient in pure water multiplied by the tortuosity coefficient), $\bar{\alpha}$ is the dispersivity tensor (m) expressed in the two main directions of anisotropy by two components, $\alpha_{\mathrm{L}}$ and $\alpha_{\mathrm{T}}$, respectively, in the longitudinal (parallel to the flow) and the transverse (perpendicular to the flow) directions, $U$ is the Darcy velocity $\left(\mathrm{m} \mathrm{s}^{-1}\right), C$ is the concentration of the solute in the mobile phase $\left(\right.$ mole $\left.\mathrm{m}^{-3}\right)$, and $q m$ (mole $\mathrm{m}^{-3} \mathrm{~s}^{-1}$ ) is a source term, expressed as a mass of the element in question, added (negative) or withdrawn (positive) per unit volume of the porous medium and per unit time. This source term represents in the present simulations the in situ production of ${ }^{4} \mathrm{He}$ within each formation. All simulations are conducted with the finite element code METIS [Goblet, 1989, 1999] in a twodimensional cross section of unit thickness.

\section{Conceptual Model}

[14] In the present study, the model takes into account four formations, two aquifers, the Carrizo and overlying Queen City and two confining layers, the Recklaw Formation that overlies the Carrizo, and the lower part of the upper-Wilcox Group together with the lower-Wilcox Group (see Figure 2a). Because of its similar facies in the study area, the latter are represented in the model as being undifferentiated. With the exception of the undifferentiated 
Wilcox Formation, all other formations have actual thickness reproduced along the entire cross section. Although the undifferentiated Wilcox Group is extremely thick, it is represented here with a constant thickness of $100 \mathrm{~m}$ (deepest layer). This is of no consequence because the transmissivity is expected to be extremely small due to the very low permeability nature of this sequence [e.g., Brinkman, 1981] and can be represented by assignment of an adequate hydraulic conductivity value.

[15] The model is represented by a triangular mesh automatically built using the DELOS code [Stab, 1995] corresponding to a stratigraphic cross section trending in a northwest-southeast direction (see Figures $1 \mathrm{~b}$ and 2a), and following the regional groundwater flow direction in the area. Because heavy withdrawal of groundwater in certain areas of the Carrizo aquifer has disturbed the distribution of the hydraulic heads, the regional water flow direction was taken as being perpendicular to the lines of equal water age as defined by Pearson [1966; see also Alexander and White, 1966]. The major grown-fault system at the end of the Carrizo aquifer is represented in the mesh by a single fault F5 (Figure 2a). Four identified minor faults of considerably less importance that intercept the cross section are also represented. With the exception of the areas proximal to the faults, the grid is composed of triangles uniformly distri-buted over the entire length of the cross section with length sizes of $50 \mathrm{~m}$, a size chosen to avoid potential numerical instabilities in areas where the Carrizo aquifer thins. In proximity to the faults, an axial distribution was imposed to the elements following a geometric series of 1:2 ratio and initial element size length of $15 \mathrm{~m}$ (Figure $2 \mathrm{~b}$ ). Faults are represented by 1-D elements that can either be active or not. In all simulations presented here, all four faults (F1, F2, F3, F4) are assumed to be nonactive. As such, the simulated water flow regime is taking place as if these faults do not exist, even though the present mesh will allow for the incorporation of those faults in later simulations. The decision to consider these minor faults inactive arose from a series of tests done on all faults, individually and simultaneously, that showed that their role is negligible on both the water flow and transport models. Tests were carried out by assigning hydraulic conductivity values to the four faults that were several orders of magnitude higher and lower than surrounding values in aquitards. The results from these tests indicate that fault hydraulic conductivity values 2 orders of magnitude above or below surrounding values have no impact on model results. These results are in agreement with lack of field evidence for any influence by the F1, F2, F3, and F4 faults on the regional and mass transport cycle. Fault F5, located the end of the cross section, is active and is represented by fifty 1-D elements. The mesh comprises a total of 58,968 triangles and 31,949 nodes and represents a cross section of $120.6 \mathrm{~km}$, with extreme altitudes relative to sea level of $+220 \mathrm{~m}$ and $-2210 \mathrm{~m}$ (Figure 2a).

\section{Groundwater Flow Simulations}

\subsection{Boundary Conditions, Calibration Data, and Parameter Values}

[16] On the basis of measured hydraulic head values available in all formations in the proximity of the cross section [cf. Harris, 1965; Alexander and White, 1966], hydraulic head values were prescribed on the outcrop areas of all formations as well as on top of the Queen City aquifer. A linear interpolation was used to prescribe head values at all nodes located in these areas. Measurements in the Queen City are available down to $86 \mathrm{~km}$ in the cross section. An interpolation of hydraulic head values for the remaining part of the cross section was applied by taking into account the relatively constant hydraulic gradient observed in this aquifer in the area, of approximately $4 \times 10^{-4}$. Because of the thickness and impermeable nature of the Wilcox Group [see Brinkman, 1981], a no-flow boundary condition was imposed at the base of the Wilcox. A high hydraulic conductivity value of $10^{-5} \mathrm{~m} \mathrm{~s}^{-1}$ was imposed on fault $\mathrm{F} 5$. This condition, together with an imposed hydraulic head at the top of the Queen City in the area, allows for the water to be evacuated upward, translating to the situation occurring at the major growth-fault system.

[17] For all scenarios presented, the hydraulic conductivity values (unknown parameters) were obtained through calibration of the model on measured hydraulic head values in the Carrizo aquifer (Figure 1a, open circles). Because of extensive well development in the Carrizo in Atascosa County since 1956 due to an extensive draught in the region, important withdrawals have occurred in the area which induced the presence of a nonsteady state regime. To reconstruct hydraulic head values prior to that extensive exploitation, three wells were used in Atascosa County for which such measurements are available previous to that period. Five additional intermediate wells in Atascosa County were used where measurements are available after development took place. In order to determine predrawdown hydraulic heads in these wells, estimates of water withdrawn [see Alexander and White, 1966] were used to estimate total water decline that occurred since 1956 . The corrected values for these five wells were used for calibration of hydraulic heads (Table 1). Average porosity values used are 20,12.5, 35, and 26\% for the Queen, Recklaw, Carrizo, and Wilcox Formations, respectively. Those given for the Carrizo aquifer represent an average measured value [cf. Pearson and White, 1967]. Porosity values for the remaining formations were estimated taking into account the dominant lithologies within each formation [e.g., Payne, 1972] and using reference values given by de Marsily [1986], Domenico and Schwartz [1998] and others.

\subsection{Groundwater Flow Model Calibration Scenarios}

[18] The nonuniqueness issue dealing with calibration of groundwater flow models will be highlighted in this particular groundwater flow system. Questions to be answered include the following: (1) Is there a high number of possible solutions that allow calibration of a particular groundwater flow model? (2) Is it nontrivial to find more than one solution? (3) If a number of solutions are possible, what is the degree of freedom available in magnitude and variation of hydraulic conductivity values? In an attempt to answer these questions and to illustrate our findings, four different calibration scenarios are presented. Some of these can be considered possible extremes to other intermediate possibilities. Sensitivity tests on hydraulic conductivity values are also presented.

\subsubsection{General Approach}

[19] An important number of sensitivity tests conducted for extremely diverse situations have shown that ground- 
Table 1. Hydraulic Head Values Used for Calibration of Groundwater Flow Models ${ }^{\mathrm{a}}$

\begin{tabular}{cccccc}
\hline $\begin{array}{c}\text { Well } \\
\text { Number }\end{array}$ & $\begin{array}{c}\text { Well } \\
\text { Name }\end{array}$ & $\begin{array}{c}\text { Depth of } \\
\text { Well, } \mathrm{m}\end{array}$ & $\begin{array}{c}\text { Measured Hydraulic } \\
\text { Head, } \mathrm{m}\end{array}$ & $\begin{array}{c}\text { Date of } \\
\text { Measurements }\end{array}$ & $\begin{array}{c}\text { Corrected Hydraulic } \\
\text { Head Values, m }\end{array}$ \\
\hline & & \multicolumn{5}{c}{ Atascosa } \\
AL-68-59-401 & AL1 & -115.8 & 161.2 & 1930 \\
AL-68-59-801 & AL2 & -195.1 & 154.5 & 1929 & \\
AL-68-59-802 & AL3 & -176.2 & 155.1 & 1929 & 151.7 \\
AL-78-03-502 & AL4 & -381.0 & 139.5 & 1964.1 \\
AL-78-03-801 & AL5 & -520.8 & 131.9 & 137.8 \\
AL-78-11-603 & AL6 & -762.0 & 131.7 & 1960 & 134.2 \\
AL-78-12-701 & AL7 & -701.0 & 118.3 & 1962 & \\
AL-78-20-101 & AL8 & -851.6 & 106.7 & 1965 & \\
& & & & & \\
SU-78-28-603 & SU9 & -1167.4 & McMullen & 1959 & \\
SU-78-37-103 & SU10 & -1368.9 & 122.5 & 1963 & \\
\hline
\end{tabular}

\footnotetext{
${ }^{a}$ Head measurements done on wells in Atascosa County after extensive pumping started at around 1956 were corrected for the drawdown that occurred since this year [cf. Alexander and White, 1966]. Altitudes of land surface for wells AL5, AL9, AL10, and AL11 are those given by the U.S. Geological Survey topographic map, Pleasanton, Texas, scale 1:100,000, 1985.

${ }^{\mathrm{b}}$ Corrected for drawdown that took place since 1956 .
}

water flow in the Carrizo aquifer is essentially dictated by the hydraulic conductivity values in this formation and that of the overlying confining layer, the Recklaw Formation. As such, the following discussion will be centered on possible hydraulic conductivity values for these two formations. Sensitivity tests carried out on hydraulic conductivity values in the Wilcox Group ranging from $10^{-8}$ to $10^{-15} \mathrm{~m} \mathrm{~s}^{-1}$ show that such variation has a negligible impact on the distribution of hydraulic head values in the Carrizo. Given these results and the very low permeability nature of this formation, we have adopted a constant hydraulic conductivity value of $10^{-11} \mathrm{~m} \mathrm{~s}^{-1}$ for all simulations, a value that is of the same order of magnitude as compared to formations with relatively similar lithologies [e.g., Castro et al., 1998a, 1998b; Burrus, 1998]. For the Queen City aquifer, where little information is available, sensitivity tests have shown that variations of hydraulic conductivity values between $10^{-4}$ and $10^{-6} \mathrm{~m} \mathrm{~s}^{-1}$ have a negligible impact on the distribution of hydraulic heads in the Carrizo. Taking into account these results together with the fact that this aquifer is productive in the study area, hydraulic conductivity values varying between $10^{-5}$ and $5 \times 10^{-5} \mathrm{~m} \mathrm{~s}^{-1}$ were adopted for this formation. At present, the Queen City aquifer does not represent our main focus of interest, and, due to lack of better data on this unit, particular attention will not be given to it in this contribution. A closer look at this formation and its hydrodynamic system is planned in the near future, when additional data on natural tracers will be available that will make possible the imposition of stronger hydrodynamic constraints to it. All simulations and calibrations presented here were achieved through a trial-and-error procedure. In the present simulations all formations are being considered isotropic.

[20] Although numerous studies have been carried out in the Carrizo aquifer and adjacent formations, a high degree of uncertainty remains concerning the functioning of this groundwater system. Regionally, most previous investigations have concentrated efforts in Atascosa County; information from McMullen County remains scarce. Pumping tests conducted in a number of wells tapping the Carrizo aquifer in Atascosa County indicate that hydraulic conductivities near the outcrop $\left(2.4 \times 10^{-4} \mathrm{~m} \mathrm{~s}^{-1}\right)$ decrease basinward to about $7 \times 10^{-5} \mathrm{~m} \mathrm{~s}^{-1} 40 \mathrm{~km}$ away [e.g., Klemt et al., 1976]. Even though questions on the actual hydraulic conductivity values remain, given the information available on the different facies of this formation and results obtained through pumping tests, it is clear that a decrease of hydraulic conductivity in the Carrizo is observed with increased distance from the recharge area. Interpretation of resistivity logs in the Recklaw formation [cf. Brinkman, $1981]$ indicate vertical hydraulic conductivity values varying between $4.7 \times 10^{-10} \mathrm{~m} \mathrm{~s}^{-1}$ and $4.7 \times 10^{-14} \mathrm{~m} \mathrm{~s}^{-1}$, i.e., variations over 4 orders of magnitude. This general information available was our starting point for the simulations conducted.

\subsubsection{Calibration Scenario 1}

[21] Scenario 1 represents a calibration for the groundwater flow system of the Carrizo and adjacent formations where a hydraulic conductivity decrease with increased distance in the Carrizo aquifer was imposed. Hydraulic conductivities for all other formations have constant values within each formation. The calibration was achieved with a hydraulic conductivity value of $7 \times 10^{-5} \mathrm{~m} \mathrm{~s}^{-1}$ at the origin of the outcrop of the Carrizo (6633 $\mathrm{m}$ away from the origin of the cross section), by imposing a decreasing factor $F=1500\left(1 /\left(x_{c}-5133\right)\right)$, where $x_{c}$ represents the distance at any point between the origin of the outcrop of this formation and the end of the cross section. The resulting hydraulic conductivity value at the end of the cross section is $9.1 \times 10^{-7} \mathrm{~m} \mathrm{~s}^{-1}$. This calibration exercise lead to prescribed hydraulic conductivity values for the Recklaw Formation and Queen City aquifer of $10^{-10} \mathrm{~m} \mathrm{~s}^{-1}$ and $10^{-5} \mathrm{~m} \mathrm{~s}^{-1}$, respectively.

[22] Calculated and measured hydraulic head values for most wells are rather close to each other, most observed deviations being $\leq 1 \%$, with the highest deviation of $2.2 \%$ observed at well AL2 (Figures $3 a$ and $3 b$ ). The distribution of hydraulic heads for this calibration scenario clearly shows the existence of upward leakage within the Recklaw Formation, as opposed to the dominant horizontal component of flow in the Carrizo and Queen City aquifers, reflecting the relatively high values of hydraulic conductivity of the latter. These findings are in agreement with previous studies, particularly those of Brinkman [1981]. Velocity distribution 
for this scenario clearly illustrates the main groundwater flow patterns within all formations. Figure $3 \mathrm{c}$ indicates the distribution of Darcy velocities where real absolute values are respected within each formation. A rather constant water velocity within the Queen City aquifer is observed with an average value of $4.1 \times 10^{-9} \mathrm{~m} \mathrm{~s}^{-1}$, as opposed to velocity values observed within the Carrizo aquifer varying from $1.2 \times 10^{-7}$ to $4.6 \times 10^{-10} \mathrm{~m} \mathrm{~s}^{-1}$, in the recharge and at the end of the cross section, respectively. This observed decrease in water velocity is due in part to the progressive decrease in hydraulic conductivity values with increased recharge distance imposed in these simulations. Because variations in velocity values are extremely important between the different formations, smallest values being observed within the Recklaw and Wilcox Formations are almost imperceptible. To highlight the main water flow directions in all formations, velocity values were normalized so that only the direction of flow is indicated (Figure 3d).

[23] For the Carrizo and Queen City aquifers, average computed infiltration rates are extremely low, about $2 \mathrm{~mm} \mathrm{yr}^{-1}$, suggesting that little recharge is taking place in these formations under these conditions. This finding is not unusual for aquifers situated within semiarid regions, which is the case for Atascosa and McMullen Counties. Historical data recorded at Dilley, a town in a neighboring county, indicate a higher average evaporation rate of $200 \mathrm{~mm} \mathrm{yr}^{-1}$ as compared to that one of precipitation $\left(57.4 \mathrm{~mm} \mathrm{yr}^{-1}\right)$ for the period between 1931 and 1960 [Alexander and White, 1966]. Similarly, no direct recharge from precipitation is taking place in the Recklaw Formation, the later being essentially recharged through upward leakage directly from the Carrizo aquifer.

[24] Taking into account the established hydraulic gradients, hydraulic conductivity values, Darcy velocities and porosity value, water travel times were calculated along streamlines within the Carrizo as follows:

$$
t=\int_{x_{0}}^{x} \frac{d x}{v}
$$

where $x_{0}$ represents the origin of a particular streamline, $x$ is a point at any distance $x$ from the origin of the streamline and $v$ is the real water velocity. Only advection is taken into account in this age estimation. Water ages calculated at calibration wells are less than $100 \mathrm{kyr}$ for recharge distances up to $45 \mathrm{~km}$, but increase considerably as distance increases reaching $653 \mathrm{kyr}$ at well SU10 (Figure 3e). Although these ages are several times older than those computed by Brinkman [1981], no real direct comparison is possible because the latter were calculated by taking into account the net sand thickness of the aquifer and are, as such, expected to be younger due to higher velocity values in these areas.

\subsubsection{Closing Remarks for Scenario 1}

[25] A possible calibration scenario for the Carrizo aquifer and surrounding formations is presented here, with plausible results on velocity values distribution, computed advection water ages, and recharge rate values for all formations. The question remains on whether or not the calibration here achieved is unique and representative of the real system. It seems clear that a decrease of hydraulic conductivities in the Carrizo aquifer is plausible, but what is the real extent of this decrease and within what ranges does it occur? To address these questions, calibration scenarios were considered that allow for a much smoother decrease in hydraulic conductivity values in the Carrizo. One of these scenarios is presented in the next section.

\subsubsection{Calibration Scenario 2}

[26] Scenario 2 again imposes a decrease in hydraulic conductivity values on the Carrizo aquifer, although one of a lower gradient, following a simple linear decrease relation given by

$$
\frac{k_{f}-k_{0}}{x_{f}-x}=\frac{k-k_{0}}{x-x_{0}}
$$

where $k_{f}$ represents the hydraulic conductivity value at the end of the cross section $x_{f}, k_{0}$ represents the hydraulic conductivity value at the origin of the Carrizo outcrop $x_{0}$, and $k$ represents the hydraulic conductivity at any point, at a distance $x$ from the origin. Calibration was achieved for a linear hydraulic conductivity decrease in the Carrizo aquifer with values varying from $5 \times 10^{-4} \mathrm{~m} \mathrm{~s}^{-1}$ to $5 \times 10^{-8} \mathrm{~m} \mathrm{~s}^{-1}$ between the recharge area and the end of the cross section, combined with constant hydraulic conductivity values for the Recklaw Formation and Queen City aquifer of $1 \times 10^{-8} \mathrm{~m} \mathrm{~s}^{-1}$ and $5 \times 10^{-5} \mathrm{~m} \mathrm{~s}^{-1}$, respectively.

[27] Scenario 2 also yielded an extremely good calibration based on hydraulic heads, with a maximum deviation of $1.6 \%$ between measured and calculated head values at well AL1 (Figures 4a and 4b). Again, similar groundwater flow patterns within the Carrizo aquifer and Recklaw Formation are observed, with a dominant horizontal water flow and decreasing water velocities with increasing recharge distance within the first formation, and a clear, strong upward leakage within the Recklaw Formation (Figures 4c and 4d). Indeed, because vertical hydraulic conductivity values assigned to this formation are now 2 orders of magnitude higher, so is the leakage flux, which is proportional to this parameter under similar differences in hydraulic gradient between the Carrizo and Queen City aquifers. As a result of this increased upward leakage in the Recklaw Formation, a major change in the groundwater flow dynamics in the Queen City is observed. Water flow in the Queen City aquifer is no longer horizontal but semivertical upward, in response to the important water flux originating from the underlying confining layer. In addition, because hydraulic conductivities and consequently water velocities at the outcrop of the Carrizo are extremely important, of the order of $8.5 \times$ $10^{-7} \mathrm{~m} \mathrm{~s}^{-1}$, infiltration rates increase to around $215 \mathrm{~mm}$ $\mathrm{yr}^{-1}$. Precipitation rates reported in Poteet for the period 1942-1964, one of the closest towns to our cross section, average $646 \mathrm{~mm} \mathrm{yr}^{-1}$ [Alexander and White, 1966]. Under these circumstances, recharge in the Carrizo aquifer would represent around $33 \%$ of the total precipitation, a seemingly high value for a semiarid region. However, recharge of the Carrizo can occur in part from the Atascosa River, which intercepts its outcrop area in this county. Owing to lack of information at present, the role played by direct river recharge of the Carrizo aquifer is not clear. Nevertheless, the potential for periodic recharge by the river reduces the percentage of direct recharge required from precipitation, making the model estimates of recharge reasonable. In contrast to the Carrizo, the Recklaw Formation and Queen 
A

a)

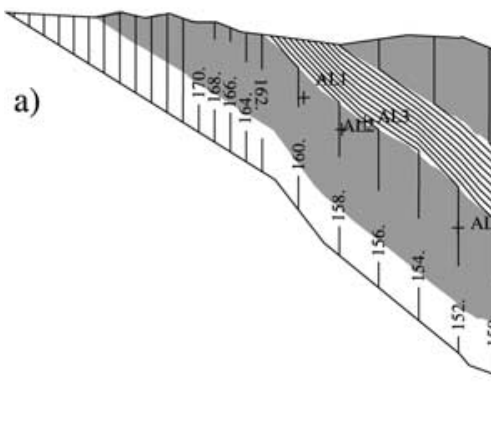<smiles>C#CCCCCCCCCC</smiles>
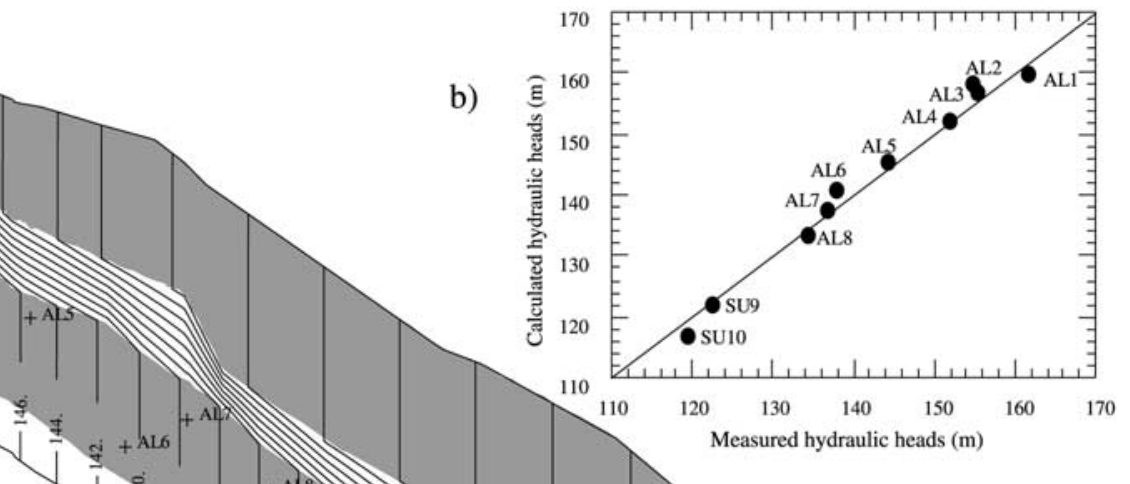

c)

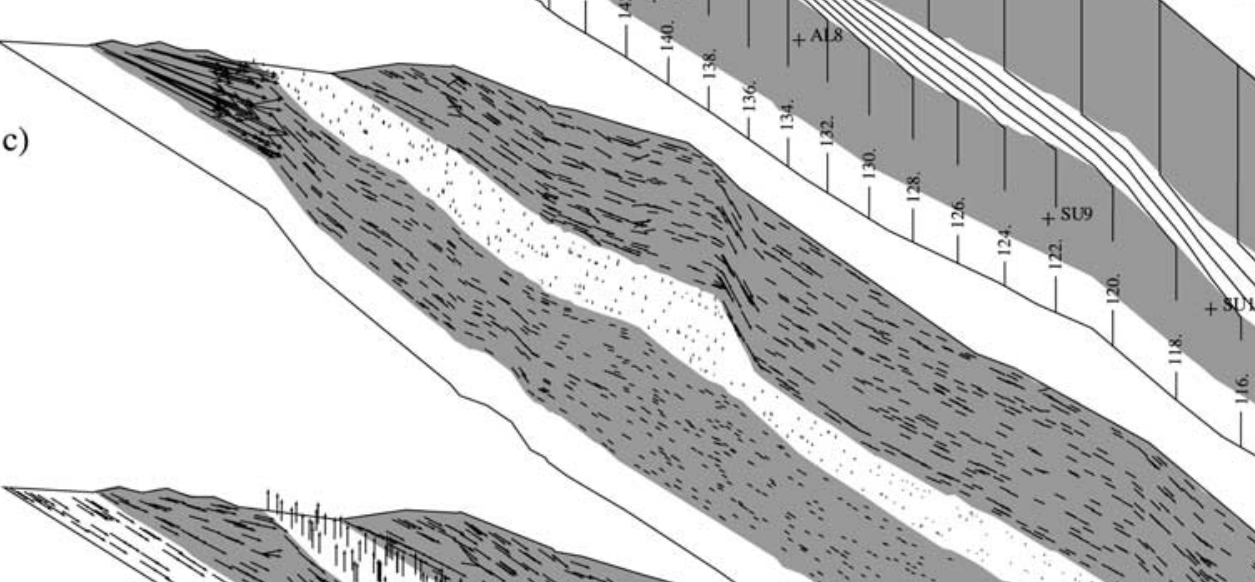

d)

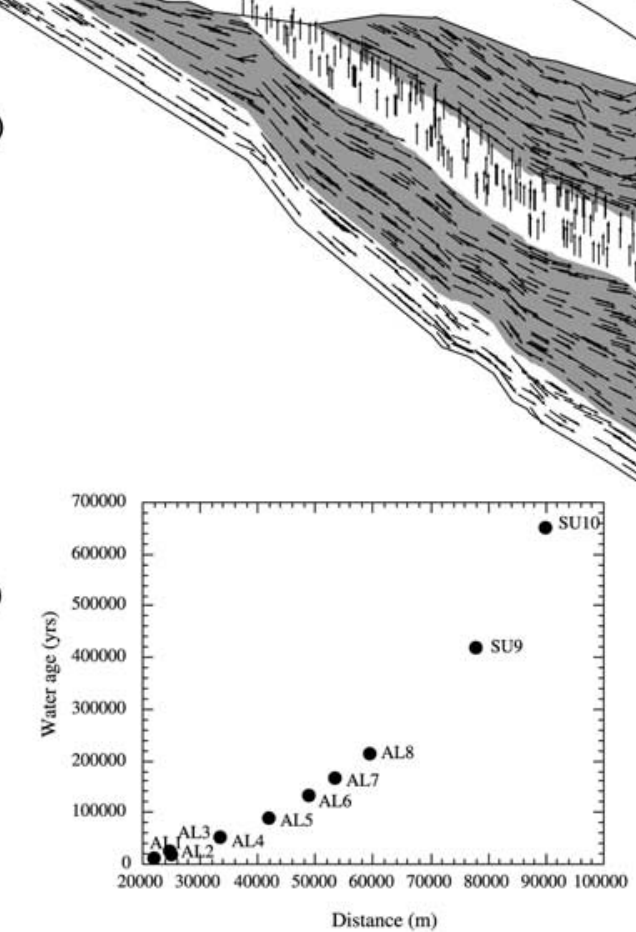

0000030004400005000060000700008000090000100000

Distance (m)

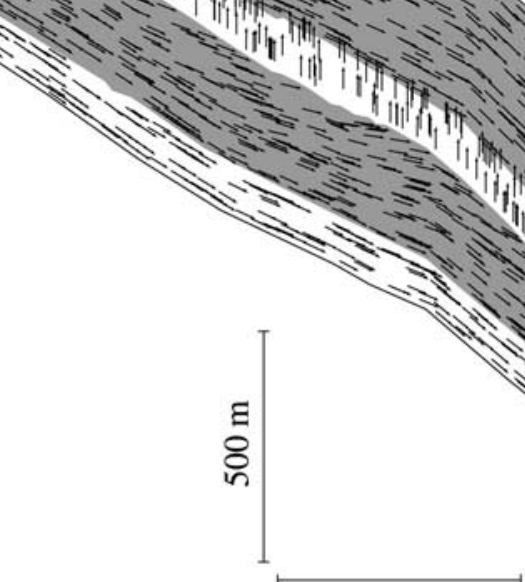

$20 \mathrm{~km}$ 
City aquifer display a deficit in outcrop infiltration. The Recklaw Formation is now clearly recharged through the Carrizo aquifer, which, in turn, recharges the Queen City aquifer. Although data on recharge rates in Atascosa County do not exist, all studies undertaken in the area suggest that direct recharge rates within the Recklaw and Queen City aquifer are negligible [see, for example, LBG-Guyton Associates, 1998].

[28] Following the same procedure as described in Scenario 1, groundwater ages were calculated for Scenario 2. In contrast to Scenario 1, estimated water ages in the Carrizo are now extremely young, several times younger as compared to those estimated by Brinkman [1981] (Figure 4e).

\subsubsection{Closing Remarks for Scenario 2}

[29] Although it was possible to obtain a calibrated groundwater flow model for the Carrizo aquifer and surrounding formations under rather different hydraulic conductivity values for the Carrizo aquifer (much higher over most of the length of the entire cross section) and Recklaw Formation ( 2 orders of magnitude higher) as compared to the previous scenario, it is not possible to definitively exclude either scenario. Questions remain on the extent of variability of hydraulic conductivity values within the Carrizo aquifer, on the closest "true values" of hydraulic conductivity in this formation, and on the gradient of decrease of such values with increased recharge distance. Similar concerns arise regarding the hydraulic conductivity values of the Recklaw Formation. Are these values approximately constant, or do they also vary and possibly decrease with increased recharge distance? If the answer is affirmative, what is the extent of such decrease? If an answer to such questions is difficult to obtain, one may choose to try to answer the following question: Is calibration of the groundwater flow model possible with decreasing values of hydraulic conductivity in the Recklaw Formation and a different variation scenario of hydraulic conductivities in place in the Carrizo aquifer? The answer seems to be affirmative. A possible calibration scenario under these conditions is presented in the next section.

\subsubsection{Calibration Scenario 3}

[30] Scenario 3 was obtained through a simultaneous exponential decrease of hydraulic conductivity values in the Carrizo aquifer and Recklaw Formation. Calibration was obtained by applying exponential decreasing factors $F_{c}=\exp -\left(\left(x_{c}-6633\right) / 12000\right)$ and $F_{r}=\exp -\left(\left(x_{r}-\right.\right.$ 19133)/12000) to the Carrizo and Recklaw, respectively, where $x_{c}$ and $x_{r}$ represent any point at a distance $x$ from the origin of the Carrizo $(6633 \mathrm{~m})$ and Recklaw $(19133 \mathrm{~m})$ outcrop areas, respectively. Initial and final hydraulic conductivity values for the Carrizo and Recklaw are $5 \times 10^{-4}$ and $3 \times 10^{-8} \mathrm{~m} \mathrm{~s}^{-1}$ and $3.8 \times 10^{-8}$ and $6.4 \times 10^{-12} \mathrm{~m} \mathrm{~s}^{-1}$, respectively. The Queen City was assigned a constant hydraulic conductivity value of $5 \times 10^{-5} \mathrm{~m} \mathrm{~s}^{-1}$.

[31] Like Scenarios 1 and 2, Scenario 3 yielded a good calibration, with a maximum deviation between calculated and measured values of $2.6 \%$ at well AL4 (see Figures 5a and $5 b$ ). Because in the outcrop areas hydraulic conductivity values are of the same order of magnitude as those of Scenario 2, with a similar strong upward leakage in the Recklaw, only in areas near the outcrop does the Queen City display a semivertical water movement. Elsewhere, direct influence of upward leakage in the Queen is no longer visible and flow in this aquifer becomes essentially horizontal in response to the rapid decrease in hydraulic conductivities of the Recklaw with increasing recharge distance (Figures $5 \mathrm{c}$ and $5 \mathrm{~d}$ ). Directions of water velocities toward the Recklaw Formation are clearly observed at the top of the Carrizo aquifer, illustrating the effectiveness of indirect recharge for this confining layer. Estimation of infiltration rates indicates that recharge is occurring in the Carrizo at a rate around $106 \mathrm{~mm} \mathrm{yr}^{-1}$, which would correspond approximately to $16 \%$ of infiltration directly from precipitation. It is possible for a contribution from the Atascosa River to be also present as previously discussed. Calculated groundwater ages are less than 100,000 years for distances up to $65 \mathrm{~km}$ (Figure 5e), with a steep increase toward the discharge area, where values are observed similar to those calculated in Scenario 1.

\subsubsection{Closing Remarks for Scenario 3}

[32] Although quite different hydrodynamic conditions were imposed in this simulation, it was still possible to construct a reasonable model that is consistent with observed properties for each formation. Scenario 3 provided no further constraints on the "real" hydraulic conductivity values or on the groundwater flow dynamics. The tests presented seem to indicate that indeed, a high degree of freedom is available to calibrate this type of regional groundwater flow model. Is it possible that the degree of freedom to calibrate such complex system is high to the point that calibration can also be achieved by simply assigning constant hydraulic conductivity values to all formations? The results presented below provide an answer to this question.

\subsubsection{Calibration Scenario 4}

[33] A new calibration was achieved by assigning constant hydraulic conductivity values to all formations. Those are $5 \times 10^{-6}, 10^{-10}$, and $10^{-5} \mathrm{~m} \mathrm{~s}^{-1}$ to the Carrizo, Recklaw, and Queen City, respectively. Figures 6a and 6b show the comparison of calculated and measured values for hydraulic heads, with a maximum observed deviation of $2 \%$. Again, the velocity distribution field (Figures 6c and 6d) indicates an essentially horizontal flow within the Carrizo

Figure 3. (opposite) (a) Distribution of calculated hydraulic heads (meters) for calibrated groundwater flow model Scenario 1. The location of wells where measured hydraulic heads were used for calibration is also indicated. (b) Measured hydraulic heads in the Carrizo aquifer plotted as a function of calculated values; line 1:1 is plotted for reference. (c) Distribution of Darcy velocities $\left(\mathrm{m} \mathrm{s}^{-1}\right)$ in the system for scenario 1; velocity vectors are more important in the Carrizo outcrop area where hydraulic conductivities are higher. They decrease toward the discharge area. Because hydraulic conductivity values are extremely small in the Wilcox as compared to the overlying layers, velocity vectors are not visible here. (d) Normalized velocity vectors for all formations so that the direction of water flow can be observed; this direction is vertical upward within the Recklaw formation, essentially horizontal within the others. (e) Calculated advective water ages (years) for all wells used for calibration of the groundwater flow model for Scenario 1, plotted as a function of distance (meters) from the beginning of the cross section (A). 
A

a)
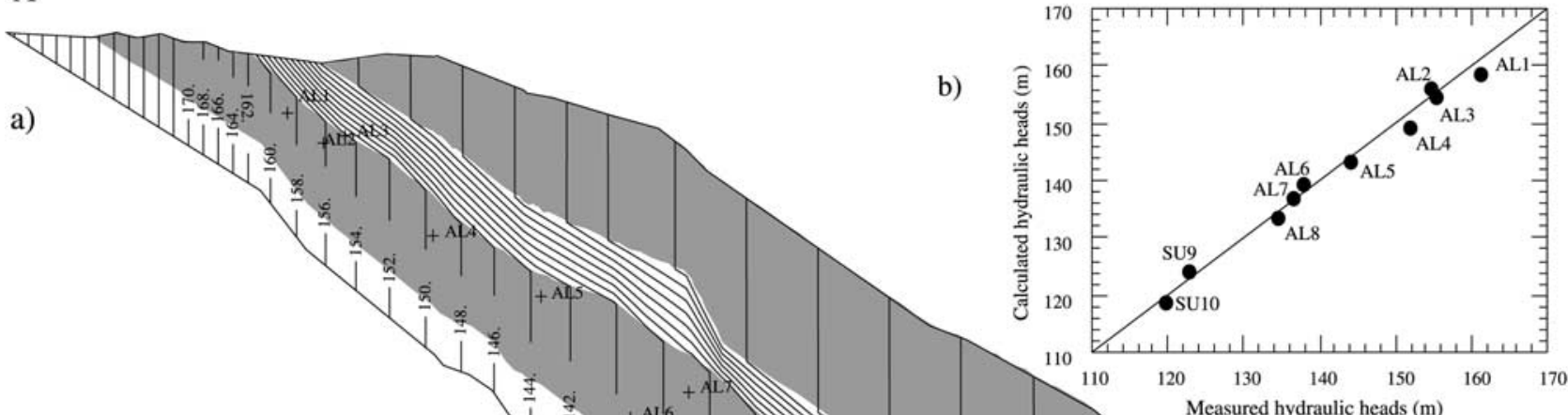

c)

d)
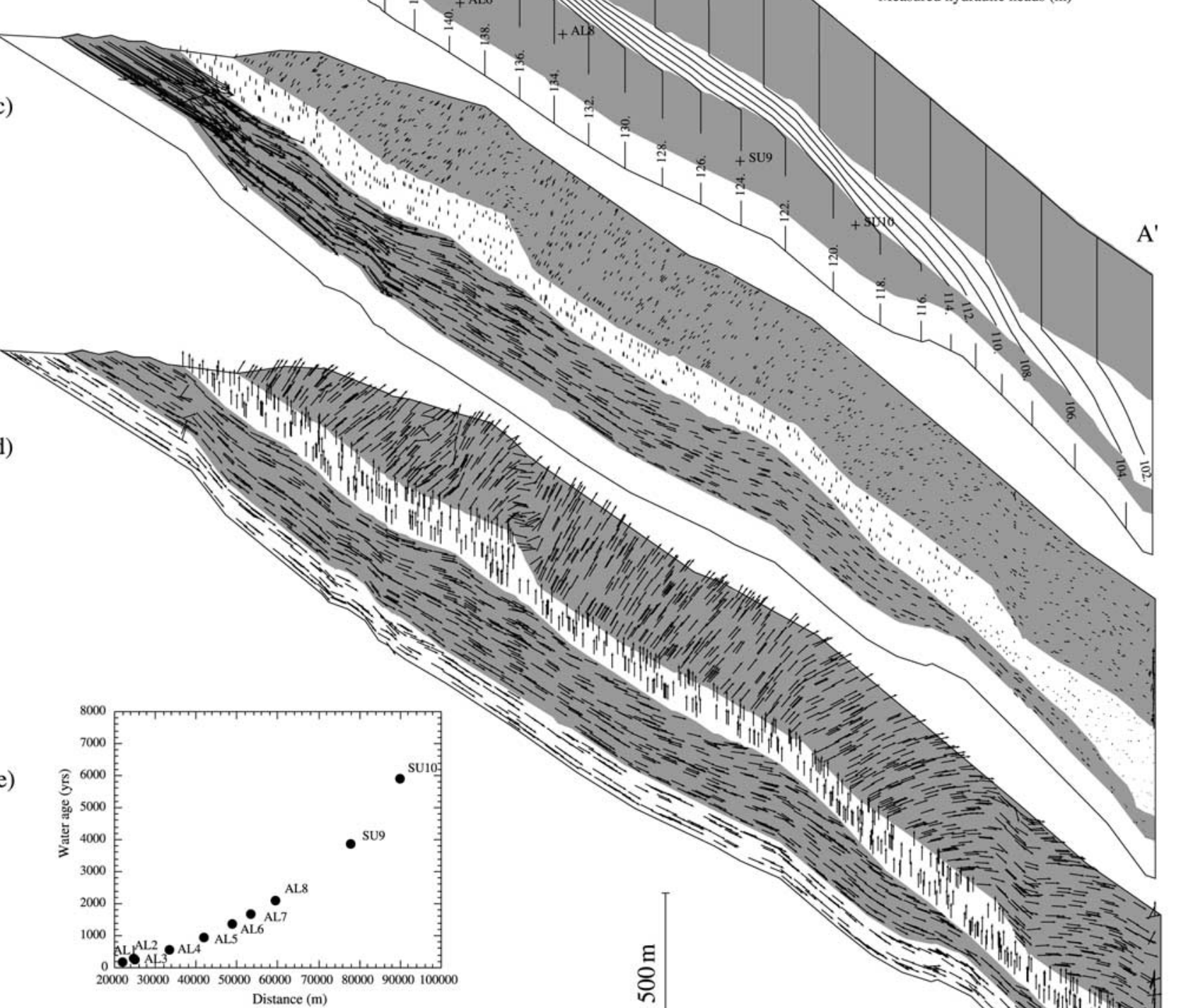

$20 \mathrm{~km}$

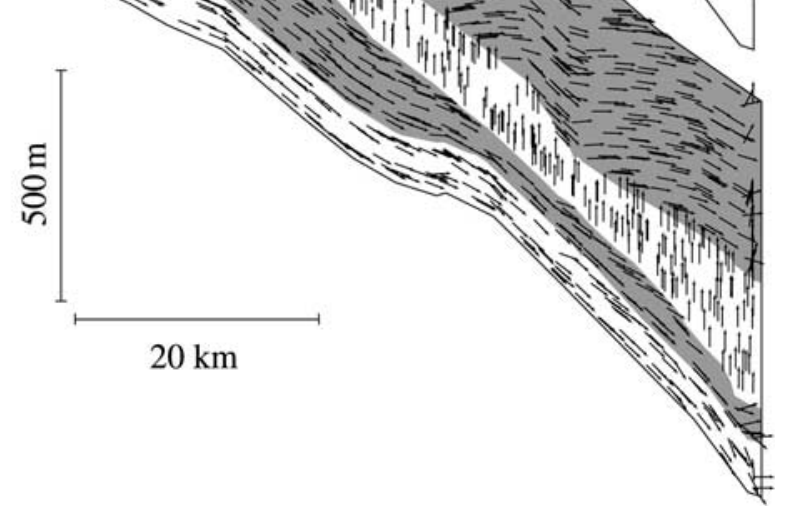


and Queen City aquifers, with average Darcy velocity values at around $5 \times 10^{-9} \mathrm{~m} \mathrm{~s}^{-1}$. Minimum recharge is occurring in these aquifers with infiltration rates at around $2 \mathrm{~mm} \mathrm{yr}^{-1}$. Upward leakage occurs in the Recklaw at a rate similar to that estimated in Scenario 1. Calculated ages for most of the cross section (Figure 6e) are considerably higher than those estimated for Scenario 3, but are similar in the first half of the cross section to those calculated for Scenario 1.

\subsubsection{Closing Remarks for Scenario 4}

[34] Although Scenario 4 is a rather simplified one, it displays once again results and patterns on velocity, recharge rates, and water ages that are not unreasonable for the study area. However, owing to the nature of the Carrizo facies in the area, one is left to consider that probably such a simple hydraulic conductivity scenario could not adequately replicate the real patterns and parameters of the actual hydrodynamic system.

\subsection{Sensitivity Tests on Hydraulic Heads}

[35] The achievement of four such different calibration scenarios for sets of hydraulic conductivity values may raise the question of whether or not in this conceptual model, hydraulic head values are sensitive at all to changes in hydraulic conductivities. In fact, the model is quite sensitive to such variations. With a few examples, the sensitivity of the model on hydraulic conductivities and its impact on calculated hydraulic heads is highlighted. To simplify this demonstration, sensitivity tests are presented by assigning constant values of hydraulic conductivity within each formation. Except when specified, all hydraulic conductivity values assigned are those of Scenario 4, which is used for direct comparison.

[36] Figure 7a shows the distribution of hydraulic heads for hydraulic conductivity values in the Carrizo aquifer 1 order of magnitude higher as compared to Scenario 4. As expected, this higher hydraulic conductivity value has induced much higher hydraulic head values as compared to the later, and the distribution of equipotential lines shows now a much stronger vertical hydraulic head loss occurring in the Recklaw Formation. Deviations up to $21 \%$ are observed between measured and calculated values (Figure 7b). On the other hand, a decrease in hydraulic conductivity values in the Carrizo of the same order will have the opposite effect, with a strong decrease observed in the distribution of hydraulic heads in this aquifer, though less pronounced as compared to the previous situation (Figures $7 \mathrm{c}$ and $7 \mathrm{~d}$ ), with the highest deviations $(8.5 \%)$ occurring at the center of the cross section. Similar changes in hydraulic conductivity values in the Recklaw Formation will have opposite effects, with values 1 order of magnitude lower inducing a general increase in hydraulic heads in the Carrizo, and vice versa. Variations of the same order of magnitude in these two formations in the same direction tend to compensate each other.

\subsection{Closing Remarks}

[37] The set of results presented highlight in a clear fashion the nonuniqueness issue associated with calibration of regional groundwater flow models. Although no conclusive answer can be given at this point concerning the "real" hydraulic conductivity distribution in the area, through the set of exercises presented, one may now have more specific answers concerning the degree of freedom available when calibrating a groundwater flow model on measured physical parameters at a regional scale. Four distinctive calibration scenarios were produced, each of which provided a plausible reconstruction of the hydrodynamic system. The comparisons of calculated versus measured hydraulic heads in the Carrizo for all scenarios synthesized in Figure 8a indicate a maximum deviation of $3.3 \%$ among all calculated values. In contrast, hydraulic conductivities assigned to the same aquifer (Figure 8b) indicate variations up to 2 orders of magnitude at certain locations, yet giving origin to very similar sets of calculated hydraulic head values. Similarly, examination of calculated ages (Figure 8c) indicates deviations of the same order. Such calibration scenarios were achieved, as seen, through a combination of different sets of hydraulic conductivities in adjacent formations and, in particular, those of the above confining layer with variations of hydraulic conductivity values over 2 orders of magnitude, between $3 \times 10^{-8}$ and $10^{-10} \mathrm{~m} \mathrm{~s}^{-1}$.

[38] Simple estimations of the flux leakage occurring in the Recklaw within the area where the Queen City remains unconfined, away approximately $30 \mathrm{~km}$ from the origin of the cross section were carried out following the Darcy's Law where the leakage flux is given by

$$
F_{l}=-K^{\prime} \frac{h_{2}-h_{1}}{n^{\prime}}
$$

where $K^{\prime}$ is the hydraulic conductivity of the aquitard, $n^{\prime}$ is its thickness, $h_{2}$ is the hydraulic head of the confined aquifer (the Carrizo in our case) and $h_{1}$ is the corresponding hydraulic head of the unconfined aquifer over the same vertical. Results, presented in Table 2, indicate leakage flux values varying between $1.6 \times 10^{-9}$ and $1.4 \times 10^{-11} \mathrm{~m} \mathrm{~s}^{-1}$, over the same area, i.e., over 2 orders of magnitude.

[39] This set of exercises provides clear answers to a number of questions previously stated, among those the following: (1) Calibration of groundwater flow models have no unique solutions; and (2) the degree of freedom available

Figure 4. (opposite) (a) Distribution of calculated hydraulic heads (meters) for calibrated groundwater flow model Scenario 2. The location of wells where measured hydraulic heads were used for calibration is also indicated. (b) Measured hydraulic heads in the Carrizo plotted as a function of calculated values; line 1:1 is plotted for reference. (c) Distribution of Darcy velocities $\left(\mathrm{m} \mathrm{s}^{-1}\right)$ in the system for scenario 2; velocity vectors are more important in the Carrizo outcrop area where hydraulic conductivities are higher. They decrease toward the discharge area. Because hydraulic conductivity values are extremely small in the Wilcox formation as compared to the overlying layers, velocity vectors are not visible here. (d) Normalized velocity vectors for all formations so that the direction of water flow can be observed; due to the strong upward leakage within the Recklaw, water flow in the Queen City is now semivertical. Water flow direction remains essentially horizontal within the Carrizo and Wilcox. (e) Calculated advective water ages (years) for all wells used for calibration of the groundwater flow model for Scenario 2, plotted as a function of distance (meters) from the beginning of the cross section (A). 
A

a)

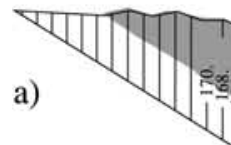

c)
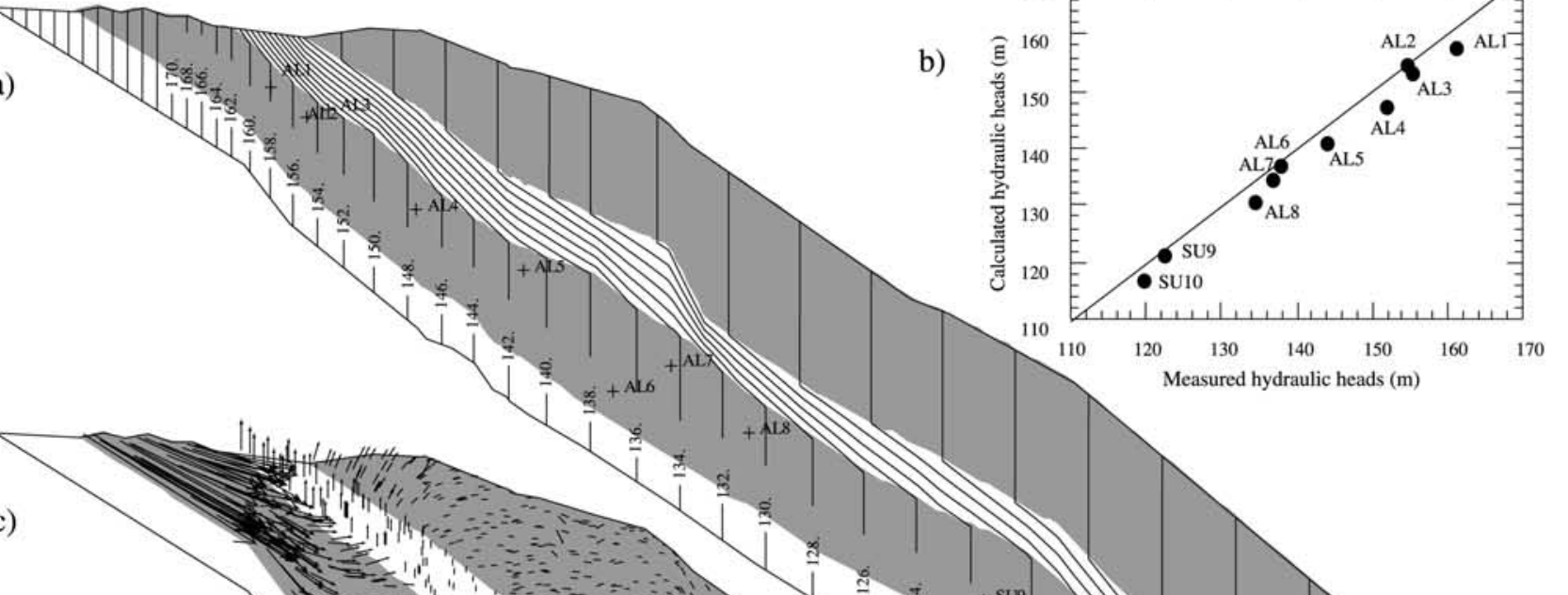

b)

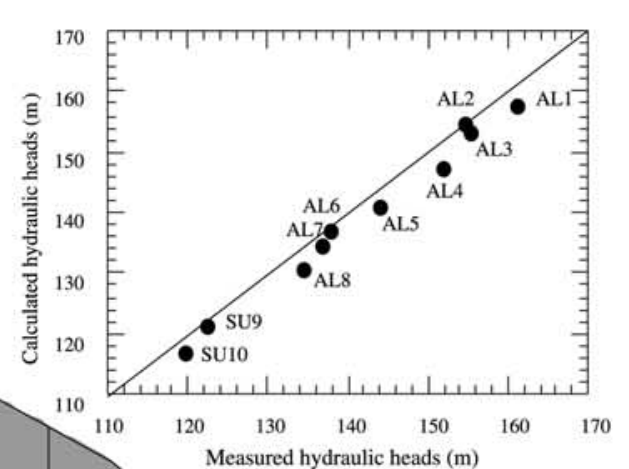

d)
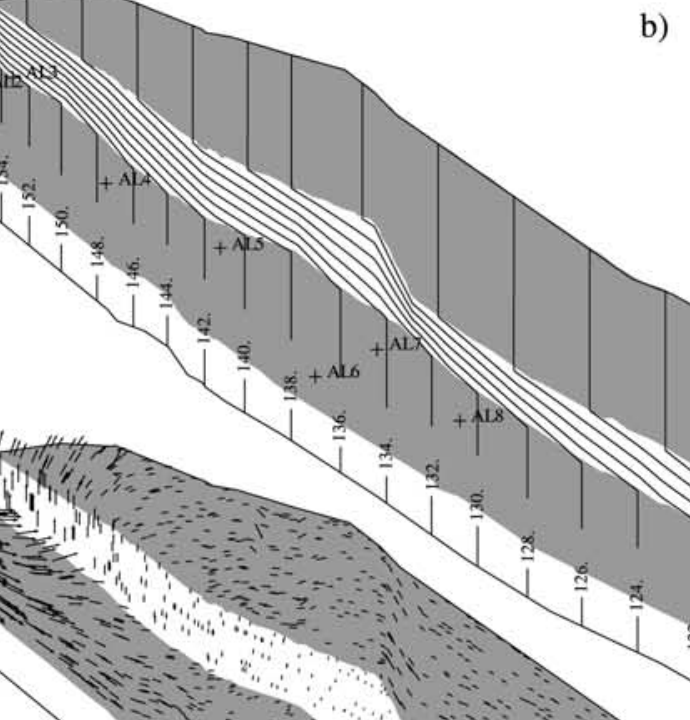

e)

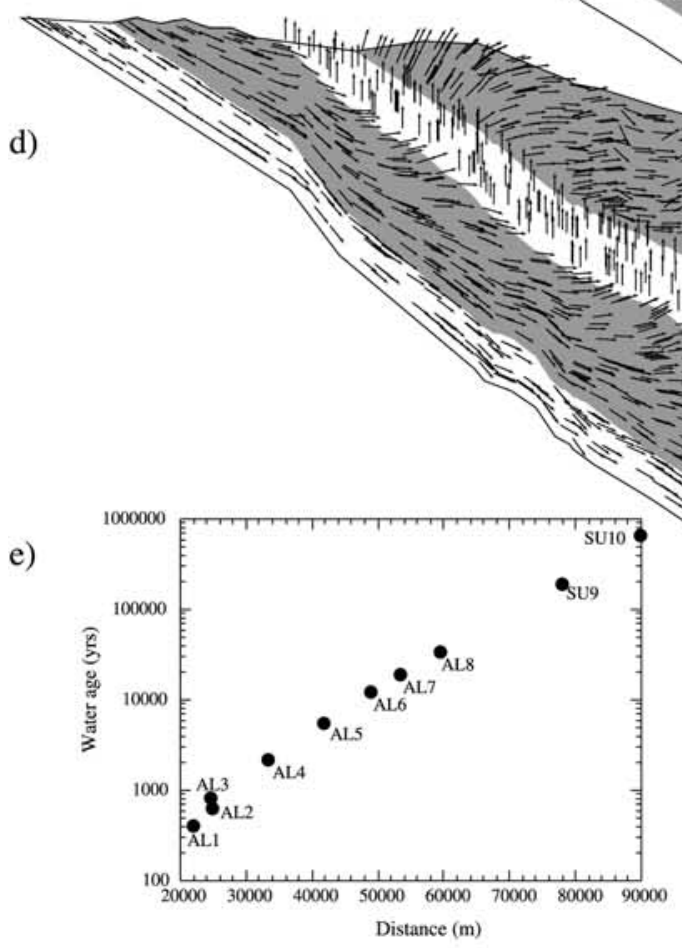

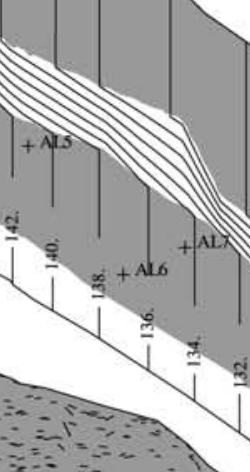

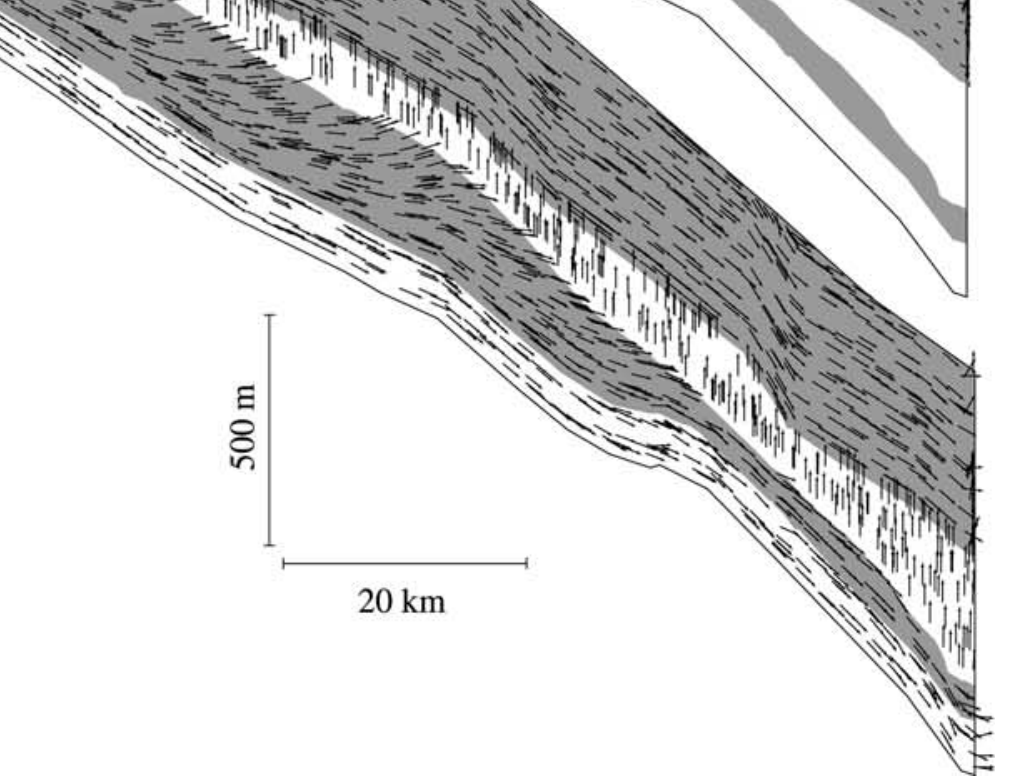


on hydraulic conductivity values is extremely high, up to 2 orders of magnitude. It also emphasizes that despite the diversity, all possible scenarios, without exception, indicate the presence of common clear patterns of the regional flow system in the area. These include that groundwater flow within the Carrizo aquifer is essentially horizontal; and vertical leakage occurs along the entire extent of the Recklaw, with indirect recharge through the Carrizo aquifer. All of the simulations and calibrations have provided a common set of characteristics which have led to an increased understanding of this particular groundwater flow system. However, unresolved are very specific questions concerning the magnitude of the hydraulic conductivity within the Carrizo aquifer, the extent of its variation with increased recharge distance, and the extent of leakage taking place in the Reklaw Formation. Without resolution of these specific questions our objective of finding a model representative of the real system is not reached and correct water ages cannot be estimated.

[40] In our quest to find specific answers on the magnitude of our key parameter, the hydraulic conductivity, a set of critical tests was carried out as suggested by Konikow and Bredehoeft [1992], in an attempt to invalidate each one of our hypothesis (model). As pointed out by Maloszewski and Zuber [1993], with additional independent data it is possible to further constrain and test the validity of each model. In the case of the Carrizo aquifer, this will be carried out with simulations of transport in the system of an independent tracer, ${ }^{4} \mathrm{He}$, whose behavior is considered to be reasonably well known in the area [see Castro et al., 2000].

\section{The ${ }^{4}$ He Transport Simulations}

\subsection{Systematics and Overview of ${ }^{4} \mathrm{He}$ Behavior in Groundwater Systems}

[41] Because of its conservative nature, ${ }^{4} \mathrm{He}$ is transported in and by the water without reacting with the reservoir rocks. Typically, ${ }^{4} \mathrm{He}$ is present in the mantle (primordial origin), in the crust (radiogenic origin), and in the atmosphere (as a consequence of the degassing of the Earth). These components of different origin present specific characteristics, which allow identification of their sources and sinks [e.g., Craig et al., 1978; Lupton, 1983; Andrews, 1985; Allegre et al., 1986; Martel et al., 1989; Ballentine et al., 1991; Honda et al., 1991; Marcantonio et al., 1998]. The concentration of ${ }^{4} \mathrm{He}$ in groundwater frequently exceeds that expected for water in solubility equilibrium with the atmosphere (air saturated water, or ASW). Commonly, most of the observed ${ }^{4} \mathrm{He}$ excesses in groundwater have a radiogenic origin where ${ }^{4} \mathrm{He}$ results from $\alpha$ decay of the natural $\mathrm{U}$ and $\mathrm{Th}$ decay series present in many common rocks in the crust. In groundwater systems, these excesses can either result from in situ production (production taking place within the groundwater system in question) or have an external origin, from deeper layers or from the crystalline basement [e.g., Torgersen and Clarke, 1985; Stute et al., 1992; Solomon et al., 1996; Castro et al., 1998a]. In the later case, ${ }^{4} \mathrm{He}$ must be transported to the upper levels either through advection, dispersion, and diffusion or a combination of each one of these transport processes.

[42] In Atascosa and McMullen counties, 22 wells in the Carrizo aquifer have been previously sampled for analysis of ${ }^{4} \mathrm{He}$ and all other noble gases [see Castro et al., 2000] (Figure 1b). Detailed analysis on the different helium components have shown excesses of ${ }^{4} \mathrm{He}$ concentrations as compared to ASW values up to 2 orders of magnitude [cf. Castro et al., 2000]. These excesses increase with distance from the outcrop area as well as with depth, translating the incorporation of radiogenic ${ }^{4} \mathrm{He}$ in the water over time that is progressively added to recharge water entering with an atmospheric ${ }^{4} \mathrm{He}$ component. These excesses are entirely of radiogenic origin and result partly from in situ production, partly from external sources.

\subsection{Boundary Conditions, Calibration Data, and Parameter Values}

[43] For the calibration of the ${ }^{4} \mathrm{He}$ transport model, only samples located on the cross section or those relatively close to it were used. They represent a total of 11 and are distributed from the outcrop toward the discharge area (Figure 1, Table 3). A diffusion coefficient value for pure water at $58^{\circ} \mathrm{C}$, the average temperature within this groundwater system, was adopted, corresponding to $1.33 \times 10^{-8}$ $\mathrm{m}^{2} \mathrm{~s}^{-1}$ [see Weiss, 1970, 1971; Ohsumi and Horibe, 1984]. Given the nature of the different formations, a tortuosity coefficient of 0.1 was adopted for the Carrizo and Queen City aquifers, a lower one of 0.05 was adopted for the Recklaw Formation. Thus parameter $d$ in equation (2) has a value of $1.33 \times 10^{-9} \mathrm{~m}^{2} \mathrm{~s}^{-1}$ on the Carrizo and Queen City aquifers, and $6.65 \times 10^{-10} \mathrm{~m}^{2} \mathrm{~s}^{-1}$ on the Recklaw Formation. All simulations were conducted with a longitudinal $\left(\alpha_{L}\right)$ and transverse $\left(\alpha_{T}\right)$ dispersivity coefficients of $125 \mathrm{~m}$ and $12.5 \mathrm{~m}$, respectively. These values have proved to be adequate for this type of scale [Goblet, 1980; Castro et al., 1998b]. Sensitivity tests conducted on this parameter

Figure 5. (opposite) (a) Distribution of calculated hydraulic heads (meters) for calibrated groundwater flow model Scenario 3. The location of wells where measured hydraulic heads were used for calibration is also indicated. (b) Measured hydraulic heads in the Carrizo plotted as a function of calculated values; line 1:1 is plotted for reference. (c) Distribution of Darcy velocities $\left(\mathrm{m} \mathrm{s}^{-1}\right)$ in the system for scenario 3; velocity vectors are much stronger in the Carrizo outcrop area, extremely small toward the discharge area, due to the exponential decrease of hydraulic conductivity assigned from the outcrop toward the discharge area. Because hydraulic conductivity values are extremely small in the Wilcox formation and toward the discharge area in the Carrizo and Recklaw formations, velocity vectors are not visible in these areas. (d) Normalized velocity vectors for all formations so that the direction of water flow can be observed; this direction is vertical upward within the Recklaw formation, essentially horizontal within the Carrizo, Wilcox, and for most of the extent of the Queen City. In the outcrop area of the Queen City, a semivertical upward water flow direction can be observed due to the strong upward leakage occurring within the Recklaw in this zone. (e) Calculated advective water ages (years) for all wells used for calibration of the groundwater flow model for Scenario 3, plotted as a function of distance (meters) from the beginning of the cross section (A). 
A

a)

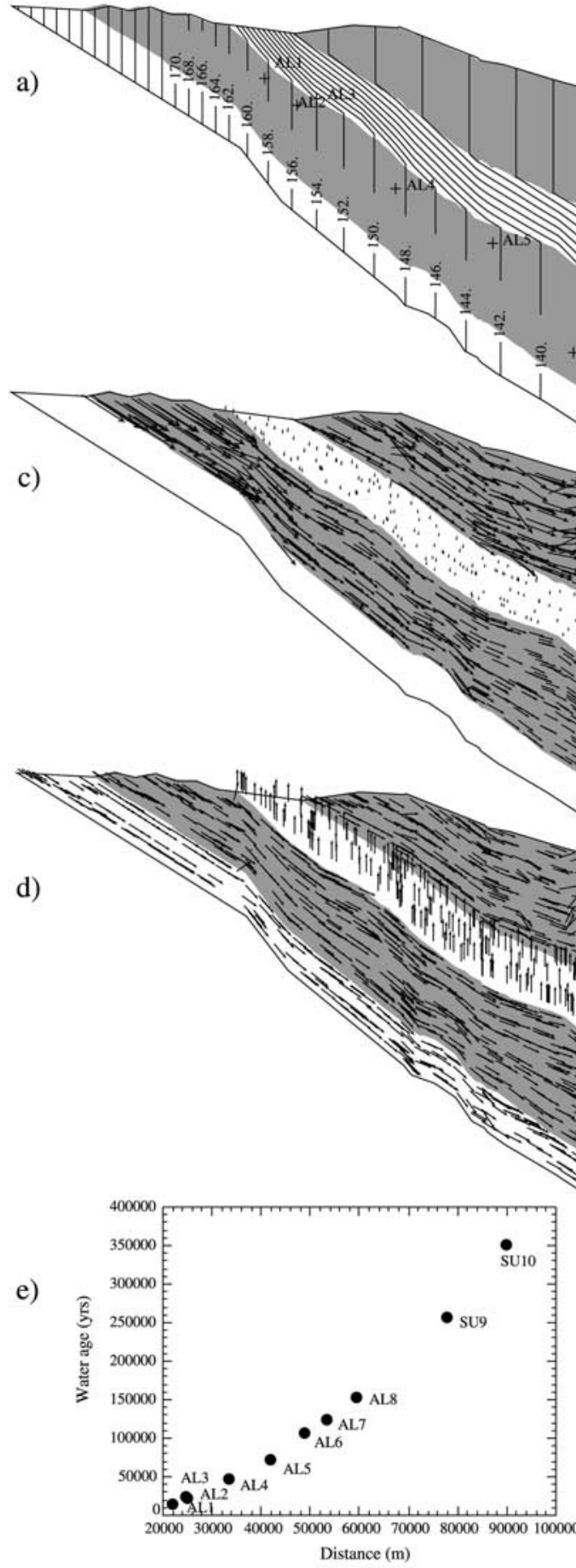

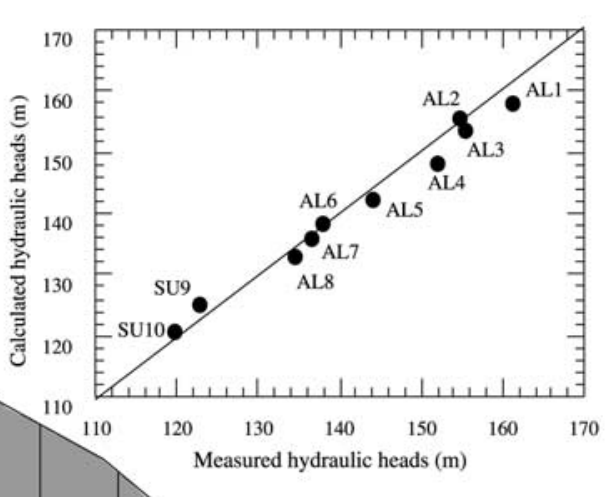


with the present model have also shown the magnitude of these values to be appropriated so that numerical instabilities are avoided.

[44] Concerning the boundary conditions, a ${ }^{4} \mathrm{He}$ concentration of $2.01 \times 10^{-6} \mathrm{~mol} \mathrm{~m}^{-3}$ corresponding to that one of ASW for a temperature of $18^{\circ} \mathrm{C}$ (the average annual temperature in the area) was prescribed at all surface nodes of the cross section (outcrop areas). On top of the Queen City, an outlet condition $(\partial C / \partial n)=0$ was prescribed, which allows for ${ }^{4} \mathrm{He}$ to be evacuated by advection through the top of the Queen. A flux value of ${ }^{4} \mathrm{He}$ entering the Carrizo aquifer was imposed to all nodes at the base of this formation. This condition, together with a prescribed null diffusion coefficient in the Wilcox, will create an upward ${ }^{4} \mathrm{He}$ flux originating at the bottom of the Carrizo aquifer. This flux value (external ${ }^{4} \mathrm{He}$ contribution) is our calibration parameter for the transport model. Inside the domain, and for the Carrizo, Recklaw, and Queen City, a source term representing the internal production $\left(\mathrm{mol} \mathrm{m}_{\text {rock }}^{-3} \mathrm{~s}^{-1}\right)$ of ${ }^{4} \mathrm{He}$ within each formation was added to all nodes. Internal ${ }^{4} \mathrm{He}$ production rates were calculated using constant decay values given by Steiger and Jager [1977] as follows:

$$
P^{4} \mathrm{He}=1.71 \times 10^{-25}[U]+4.06 \times 10^{-26}[\mathrm{Th}] \mathrm{mol} \mathrm{g}_{\text {rock }}^{-1} \mathrm{~s}^{-1}
$$

where $[U]$ and $[T h]$ represent the $U$ and Th concentrations (in ppm) in the reservoirs rocks, respectively (Table 4). For all simulations it is assumed that this isotope is released to the water at the production rate [see Torgersen, 1980; Torgersen and Clarke, 1985].

\subsection{Tests of ${ }^{4} \mathrm{He}$ Transport Model on Calibrated Groundwater Flow Scenarios}

[45] We will consider at present that a reasonable knowledge of the ${ }^{4} \mathrm{He}$ behavior in the system has been acquired. The parameters required to construct the ${ }^{4} \mathrm{He}$ transport conceptual model were either measured (e.g., concentrations of ${ }^{4} \mathrm{He}$, concentrations of isotope parents in the reservoir rock) or chosen within reasonable values (e.g., diffusion and tortuosity coefficient values). In this situation, we are left with one single unknown parameter, the external ${ }^{4} \mathrm{He}$ flux value entering the bottom of the Carrizo aquifer to attempt calibration of the transport model for each one of the calibrated groundwater flow scenarios. Scenarios 1, 2, and 4 and their respective groundwater flow models were invalidated because they each failed calibration by the ${ }^{4} \mathrm{He}$ transport model; these are presented first. Calibration of the ${ }^{4} \mathrm{He}$ transport model was achieved for Scenario 3; thus we consider that this groundwater flow model is presently validated by ${ }^{4} \mathrm{He}$. These results are presented at the end of this section.

\subsubsection{Invalidation of Calibrated Groundwater Models 6.3.1.1. Scenario 1}

[46] Tests conducted on the external ${ }^{4} \mathrm{He}$ flux entering the base of the Carrizo aquifer under groundwater flow conditions of Scenario 1 were carried out over 5 orders of magnitude, from $10^{-13}$ to $10^{-18} \mathrm{~mol} \mathrm{~m}_{\text {rock }}^{-2} \mathrm{~s}^{-1}$. The upper value corresponds approximately to the crustal flux value found in the Paris Basin [cf. Castro et al., 1998b], which is of the same order of magnitude as values of terrestrial whole crustal flux for this isotope [e.g., O'Nions and Oxburgh, 1983]. Lower ${ }^{4} \mathrm{He}$ flux values, in the range of 3.3 to $23.2 \times$ $10^{-16} \mathrm{~mol} \mathrm{~m}_{\text {rock }}^{-2} \mathrm{~s}^{-1}$ were found in the Great Hungarian Plain [cf. Stute et al., 1992]. By testing this whole range of values, we feel that all possible reasonable scenarios are covered from what is assumed to be representative of the entire ${ }^{4} \mathrm{He}$ Earth crustal flux.

[47] Using Scenario 1 conditions and a ${ }^{4} \mathrm{He}$ flux value of $5 \times 10^{-16} \mathrm{~mol} \mathrm{~m}_{\text {rock }}^{-2} \mathrm{~s}^{-1}$, it is clear that calculated ${ }^{4} \mathrm{He}$ concentrations are far too high for most of the cross section and up to 9 times the measured concentration for sample TX06 (Figure 9a). However, concentrations for this flux value are equivalent to those measured at the vicinity of the recharge area (samples TX02 and TX32) and toward the end of the cross section (samples TX26, 27). In an attempt to reduce the observed discrepancies, lower ${ }^{4} \mathrm{He}$ flux values were imposed. Although the strong discrepancies observed at the center of the cross section were reduced for a flux value of $5 \times 10^{-17} \mathrm{~mol} \mathrm{~m}_{\text {rock }}^{-2} \mathrm{~s}^{-1}$, they remain extremely important, up to 6 times the measured values. On the contrary, calculated values for samples located toward the end of the cross section are now lower than the measured values, up to one and an half times (Figure 9a). An interesting feature to note is that calculated concentrations at the proximity of the recharge area remained unchanged despite this marked reduction of ${ }^{4} \mathrm{He}$ external flux entering the Carrizo aquifer. This suggests that in this area with groundwater flow conditions of Scenario 1 , the external ${ }^{4} \mathrm{He}$ flux is not the parameter controlling ${ }^{4} \mathrm{He}$ concentrations. The question arises of whether or not it would be possible under this groundwater flow regime to reduce sufficiently the flux value so that major discrepancies between measured and calculated concentrations would disappear. In quest for an answer, lower flux values down to $10^{-18} \mathrm{~mol}$ $\mathrm{m}_{\text {rock }}^{-2} \mathrm{~s}^{-1}$ were imposed. The results obtained show clearly that for flux values inferior to $5 \times 10^{-17} \mathrm{~mol} \mathrm{~m}_{\text {rock }}^{-2} \mathrm{~s}^{-1}$, calculated concentrations are no longer dependent on the external flux but instead on the contribution from in situ production (Figure 9a). Calculated ${ }^{4} \mathrm{He}$ concentrations for a flux corresponding to $5 \times 10^{-18} \mathrm{~mol} \mathrm{~m}_{\text {rock }}^{-2} \mathrm{~s}^{-1}$ remain unchanged, and importantly, even where no ${ }^{4} \mathrm{He}$ external flux would be present. In the later, only the internal production within the Carrizo is responsible for the radio-

Figure 6. (opposite) (a) Distribution of calculated hydraulic heads (meters) for calibrated groundwater flow model Scenario 4. The location of wells where measured hydraulic heads were used for calibration is also indicated. (b) Measured hydraulic heads in the Carrizo plotted as a function of calculated values; line 1:1 is plotted for reference. (c) Distribution of Darcy velocities $\left(\mathrm{m} \mathrm{s}^{-1}\right)$ in the system for scenario 4; velocity vectors are stronger in the Carrizo outcrop area as compared to the discharge area. Because hydraulic conductivity values are extremely small in the Wilcox formation, velocity vectors are not visible here. (d) Normalized velocity vectors for all formations so that the direction of water flow can be observed; this direction is vertical upward within the Recklaw, essentially horizontal within the other formations. (e) Calculated advective water ages (years) for all wells used for calibration of the groundwater flow model for scenario 4, plotted as a function of distance (meters) from the beginning of the cross section (A). 
A

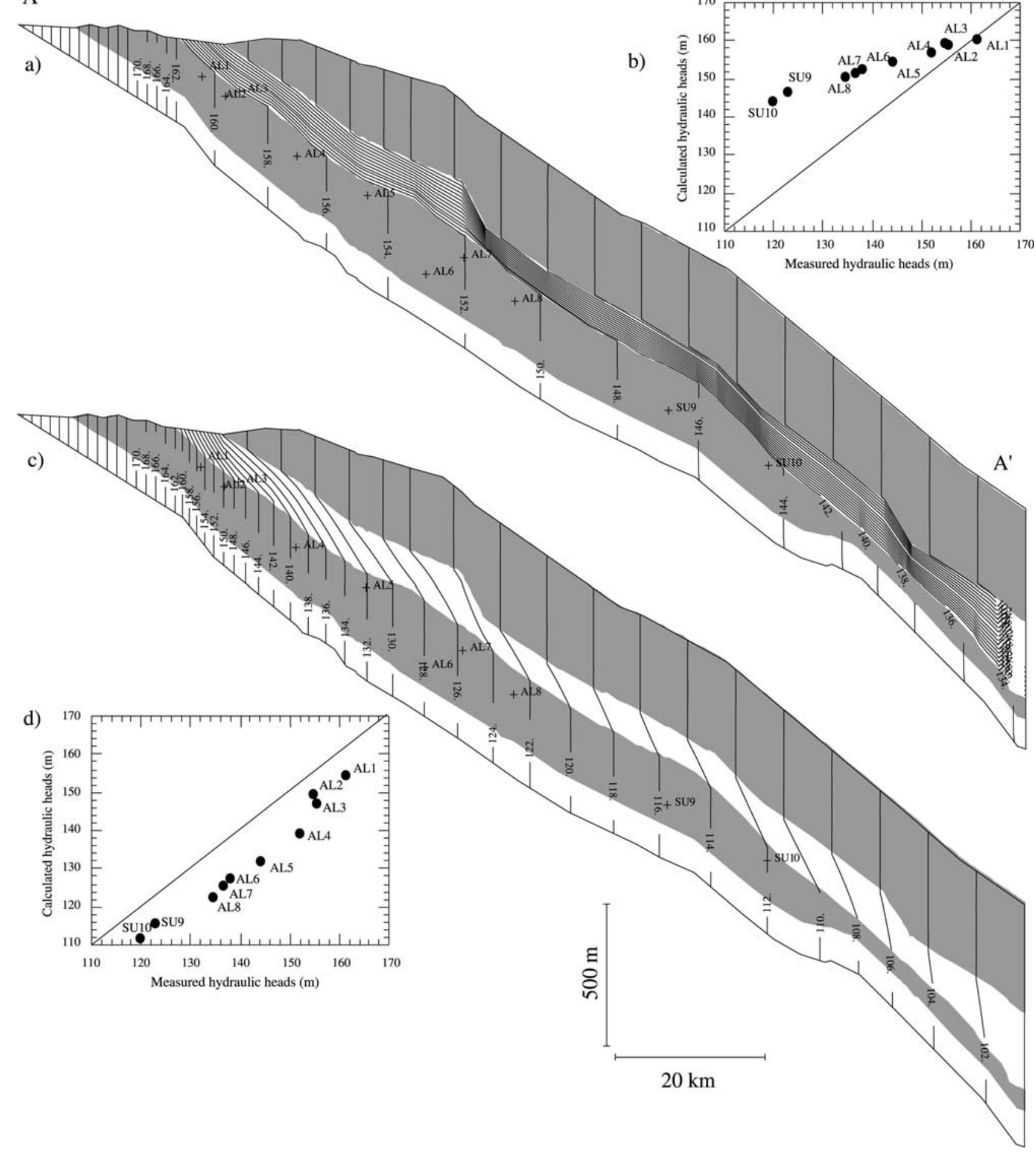

Figure 7. (a) Distribution of calculated hydraulic heads (meters). All parameters are the same as those of Figure 6 (Scenario 4) except for the hydraulic conductivity prescribed to the Carrizo, which is 1 order of magnitude higher. (b) Measured hydraulic heads in the Carrizo aquifer plotted as a function of calculated values for situation corresponding to Figure 7a; line 1:1 is plotted for reference. (c) Distribution of calculated hydraulic heads (meters) using same parameters as of Scenario 4 (Figure 6) except for the hydraulic conductivity of the Carrizo, which is 1 order of magnitude lower. (d) Measured hydraulic heads in the Carrizo plotted as a function of calculated values for situation corresponding to Figure $7 \mathrm{c}$. 

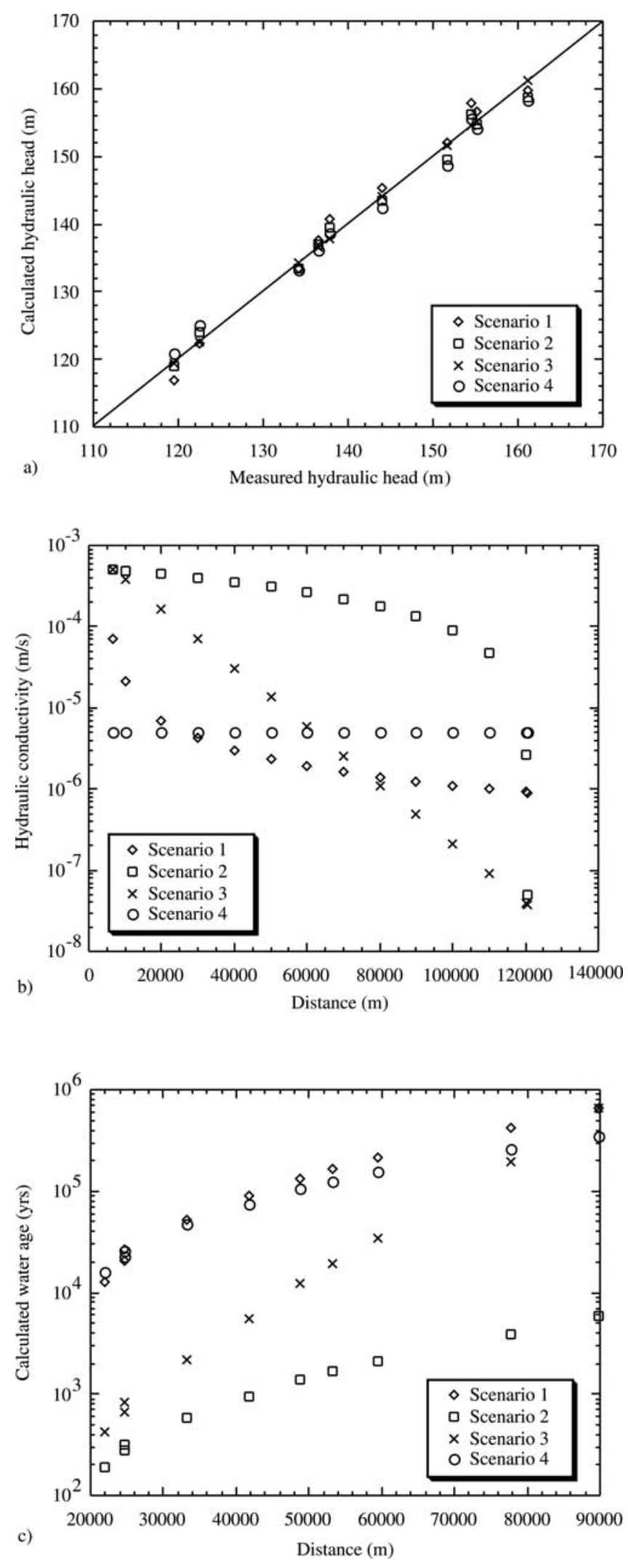

Table 2. Calculated Upward Leakage Flux $\left(F_{1}\right)$ Taking Place in the Recklaw for All Calibrated Groundwater Flow Scenarios at a Distance $30 \mathrm{~km}$ Away From the Origin of the Cross Section ${ }^{\mathrm{a}}$

\begin{tabular}{cccc}
\hline Scenario & $K^{\prime}, \mathrm{m} \mathrm{s}^{-1}$ & $h_{2}, \mathrm{~m}$ & $F_{1}, \mathrm{~m} \mathrm{~s}^{-1}$ \\
\hline 1 & $1.0 \mathrm{E}-10$ & 154.5 & $-1.7 \mathrm{E}-11$ \\
2 & $1.0 \mathrm{E}-08$ & 152.2 & $-1.5 \mathrm{E}-09$ \\
3 & $1.2 \mathrm{E}-08$ & 150.3 & $-1.6 \mathrm{E}-09$ \\
4 & $1.0 \mathrm{E}-10$ & 151.3 & $-1.4 \mathrm{E}-11$ \\
\hline
\end{tabular}

${ }^{\text {a}}$ Hydraulic head values within the Carrizo $\left(h_{2}\right)$ as well as hydraulic conductivity values $\left(K^{\prime}\right)$ for the Recklaw Formation in this area for all scenarios are also indicated. Here $n^{\prime}=117.33 \mathrm{~m}, h_{1}=134.9 \mathrm{~m}$.

genic ${ }^{4} \mathrm{He}$ present in the area. After a number of sensitivity tests carried out on flux values, it was concluded that only with a total absence of external flux and a significant reduction of the in situ production within most of the extension of the Carrizo would it be possible to calibrate the distribution of ${ }^{4} \mathrm{He}$ concentrations under the present groundwater flow conditions. Is such situation plausible? Such possibility is unlikely based on measurements of $\mathrm{U}$ and $\mathrm{Th}$ in this formation and a number of other observations. Indeed, ${ }^{4} \mathrm{He}$ production rates employed for all simulations were estimated using $\mathrm{U}$ and $\mathrm{Th}$ measurements from the most representative sample within this formation [see Castro et al., 2000]. This rock sample has a concentration of $U$ that is below the average calculated for all measured samples and similar average values of Th concentrations. As such, internal production rates of ${ }^{4} \mathrm{He}$ in the area would, at most, be underestimated. The question remains whether release of ${ }^{4} \mathrm{He}$ from the reservoir rocks is occurring at different rates in different areas of the Carrizo. This possibility is unlikely as there is no evidence for the presence of major lithologic changes in rocks/minerals producing most of the ${ }^{4} \mathrm{He}$ in the Carrizo in this area. Therefore it seems reasonable to exclude such scenario. Nevertheless, let us assume for a moment that such scenario is possible. As previously stated, only with a total absence of an external ${ }^{4} \mathrm{He}$ flux within most of the Carrizo would it be possible to calibrate the ${ }^{4} \mathrm{He}$ transport model if, simultaneously and arbitrarily, one would manipulate the release rates of this isotope from the rock within different parts of this formation. However, it is of general knowledge that the Earth's atmosphere is continuously being formed by the flux of these gases which are continuously produced in the interior of our planet. These gases are transported to the atmosphere through the crust by advection, dispersion, and/or diffusion in areas where groundwater is immobile. As such, it is not plausible that this general degassing of the Earth would not

Figure 8. (opposite) (a) Measured hydraulic head values in the Carrizo aquifer plotted as a function of calculated hydraulic head (meters) values for all groundwater flow calibrated scenarios (1, 2, 3, and 4). (b) Hydraulic conductivity values assigned to the Carrizo aquifer for all groundwater flow calibrated scenarios plotted as a function of distance from the beginning of the cross section (A). (c) Calculated water ages (years) in the Carrizo aquifer for all groundwater flow calibrated scenarios plotted as a function of distance from the beginning of the cross section. 
Table 3. Helium Isotope Concentrations of Samples Collected in the Carrizo Aquifer Used for Comparison With Calculated Concentration Values From Transport Model Simulations ${ }^{a}$

\begin{tabular}{cccc}
\hline $\begin{array}{c}\text { Well } \\
\text { Sample }\end{array}$ & $\begin{array}{c}\text { Distance From Origin } \\
\text { of Cross Section, km }\end{array}$ & $\begin{array}{c}\text { Depth, m } \\
\text { (ASL) }\end{array}$ & $\begin{array}{c}{ }^{4} \mathrm{He}, \\
\text { mol m}^{-3}\end{array}$ \\
\hline Tx 02 & 13.4 & 154.0 & $2.052 \mathrm{E}-06$ \\
Tx 04 & 61.4 & -787.0 & $1.713 \mathrm{E}-05$ \\
Tx 06 & 37.2 & -302.7 & $3.882 \mathrm{E}-06$ \\
Tx 20 & 73.8 & -942.5 & $5.505 \mathrm{E}-05$ \\
Tx 21 & 43.1 & -430.4 & $5.488 \mathrm{E}-06$ \\
Tx 25 & 76.9 & -1063.5 & $7.411 \mathrm{E}-05$ \\
Tx 26 & 87.6 & -1219.5 & $2.009 \mathrm{E}-04$ \\
Tx 27 & 93.4 & -1318.0 & $2.658 \mathrm{E}-04$ \\
Tx 29 & 77.8 & -1050.1 & $8.057 \mathrm{E}-05$ \\
Tx 32 & 11.5 & 153.0 & $3.034 \mathrm{E}-06$ \\
Tx 33 & 73.2 & -1122.9 & $5.318 \mathrm{E}-05$ \\
ASW $\left(18^{\circ} \mathrm{C}\right)^{\mathrm{b}}$ & & & $2.010 \mathrm{E}-06$ \\
\hline
\end{tabular}

${ }^{\text {a }}$ See Castro et al. [2000]. The name of the well samples is indicated as well as its distance from the origin of the cross section (A) and its depth. The ${ }^{4} \mathrm{He}$ concentration for the air saturated water (water in solubility equilibrium with the atmosphere) for the annual average temperature in the area $\left(18^{\circ} \mathrm{C}\right)$ is also indicated for comparison.

${ }^{\mathrm{b}}$ After Stute et al. [1992].

be taking place only in Atascosa and McMullen Counties, and therefore no external ${ }^{4} \mathrm{He}$ flux would be present even if very small. Through our direct measurements, observations, simulations, and sensitivity tests on the ${ }^{4} \mathrm{He}$ transport model, we consider, at our present state of knowledge of this isotope, that groundwater flow corresponding to Scenario 1 does not support in a coherent manner the behavior of this isotope. We therefore invalidate the correspondent calibrated groundwater flow model and suggest that it is inadequate for this area and system.

\subsubsection{Scenario 2}

[48] Scenario 2 exhibits extremely high hydraulic conductivity values and therefore high water velocity values over most of the extension of the Carrizo (see Figure $8 b$ ). As such, it is expected that if calibration of ${ }^{4} \mathrm{He}$ transport in the area can be achieved, a rather strong external flux value will be required so that the dilution effect exerted by recharge water entering the Carrizo aquifer will be compensated by the former. Tests on flux values between $10^{-13}$ and zero mol m $\mathrm{m}_{\text {rock }}^{-2} \mathrm{~s}^{-1}$ were carried out (Figure 9b). It is clear that calculated ${ }^{4} \mathrm{He}$ concentrations corresponding to a flux value of $10^{-13} \mathrm{~mol} \mathrm{~m}_{\text {rock }}^{-2} \mathrm{~s}^{-1}$ are extremely high as compared to the measured values, up to 7 times that of the measured concentration of sample TX06. However, such calculated concentrations are similar to the measured values for samples TX26 and 27, at about $85 \mathrm{~km}$ away from the Carrizo outcrop area. Such a strong ${ }^{4} \mathrm{He}$ crustal flux, representative of the whole terrestrial flux, has only been estimated in areas where sedimentary basins are directly in contact with crystalline basements under conditions where granites and other rocks are present that constitute major producers of ${ }^{4} \mathrm{He}$ (e.g. Paris Basin [cf. Castro et al., 1998a, 1998b]). Furthermore, variations of ${ }^{4} \mathrm{He}$ crustal flux over more than 1 order of magnitude between areas at the proximity of the outcrop and at about $85 \mathrm{~km}$ (samples TX26, 27) would be required to achieve calibration of the transport model. In the study area there is no geological evidence to explain such a strong flux increase, and $U$ and Th deposits in those areas are not known that could explain such variation. In addition, following the observed trend in flux increase toward the end of the Carrizo aquifer, ${ }^{4} \mathrm{He}$ crustal fluxes much higher than the terrestrial whole ${ }^{4} \mathrm{He}$ flux value would likely have to be present for calibration of the transport model to be achieved. Owing to lack of geological evidence to support such strong changes between the outcrop and discharge area and from acquired general knowledge on ${ }^{4} \mathrm{He}$ terrestrial fluxes and behavior, we consider that the groundwater flow model corresponding to Scenario 2 cannot explain in a coherent manner a plausible ${ }^{4} \mathrm{He}$ transport model in the area. As such, Scenario 2 is invalidated by the ${ }^{4} \mathrm{He}$ transport model.

\subsubsection{Scenario 4}

[49] The ${ }^{4} \mathrm{He}$ fluxes varying between $10^{-15}$ and $5 \times$ $10^{-17} \mathrm{~mol} \mathrm{~m}_{\text {rock }}^{-2} \mathrm{~s}^{-1}$ as well as a zero flux were imposed under conditions of groundwater flow Scenario 4 (Figure 9c). With the exception of the outcrop area, calculated ${ }^{4} \mathrm{He}$ concentrations are extremely high for all imposed flux values throughout most of the Carrizo aquifer. This also holds true for those concentrations where a zero flux was imposed, and only in situ production is responsible for the calculated concentrations. This is because (as was the case for Scenario 1) groundwater ages are extremely old, allowing for excessive accumulation of ${ }^{4} \mathrm{He}$. Thus simple accumulation of ${ }^{4} \mathrm{He}$ resulting only from in situ production produces high ${ }^{4} \mathrm{He}$ concentrations in the Carrizo, several times in excess of measured values, and up to 4.5 times those of sample TX06. Under such groundwater flow conditions, calibration could only be achieved with total absence of an external ${ }^{4} \mathrm{He}$ flux for most of the Carrizo, and by simultaneously and arbitrarily manipulating ${ }^{4} \mathrm{He}$ release rates as previously concluded for Scenario 1. Furthermore, at $70 \mathrm{~km}$ from the outcrop area, a flux value of around $1.5 \times 10^{-15}$ $\mathrm{mol} \mathrm{m} \mathrm{m}_{\text {rock }}^{-2} \mathrm{~s}^{-1}$ would have to be imposed to account for the measured concentrations at this location. Because no geological, geochemical, or mineralogical evidence exists that can account for the absence of an external flux over one locality and not another, as well as random contributions of in situ production, we conclude that groundwater flow conditions corresponding to Scenario 4 are not viable to reproduce a coherent ${ }^{4} \mathrm{He}$ transport model for this area.

\subsubsection{Validation of the Calibrated Groundwater Flow Model for Scenario 3}

[50] On the basis of our present knowledge of ${ }^{4} \mathrm{He}$ behavior in the Carrizo aquifer, valid, coherent arguments have been presented that indicate the nonviability of a

Table 4. Measured and Estimated $U$ and Th Content in the Reservoir Rocks of the Carrizo, Recklaw, and Queen City Formations, as Well as Calculated Radiogenic Production Rates of ${ }^{4} \mathrm{He}$ in These Formations

\begin{tabular}{ccccc}
\hline Formation & $\begin{array}{c}\text { Th, } \\
\mathrm{ppm}\end{array}$ & $\begin{array}{c}\mathrm{U}, \\
\mathrm{ppm}\end{array}$ & $\begin{array}{c}\text { Density, } \\
\mathrm{g} \mathrm{cm}^{-3}\end{array}$ & $\begin{array}{c}\mathrm{P}\left({ }^{4} \mathrm{He}\right), \\
\mathrm{mol} \mathrm{m}_{\text {rock }}{ }^{-3} \mathrm{~s}^{-1}\end{array}$ \\
\hline Queen $^{\mathrm{b}}$ & 6.85 & 2.08 & 2.4 & $1.49 \mathrm{E}-18$ \\
Recklaw $^{\mathrm{b}}$ & 9.425 & 2.89 & 1.7 & $1.45 \mathrm{E}-18$ \\
Carrizo $^{\mathrm{c}}$ & 2.9 & 7.50 & 2.4 & $3.33 \mathrm{E}-18$ \\
\hline
\end{tabular}

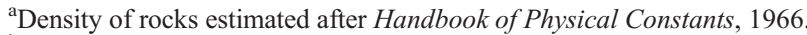

${ }^{\mathrm{b}}$ Values estimated from average lithologic composition of each formation and after Parker [1967].

${ }^{\mathrm{c}}$ Measured $\mathrm{U}$ and Th concentrations in the reservoir rock [Castro et al., $2000]$. 

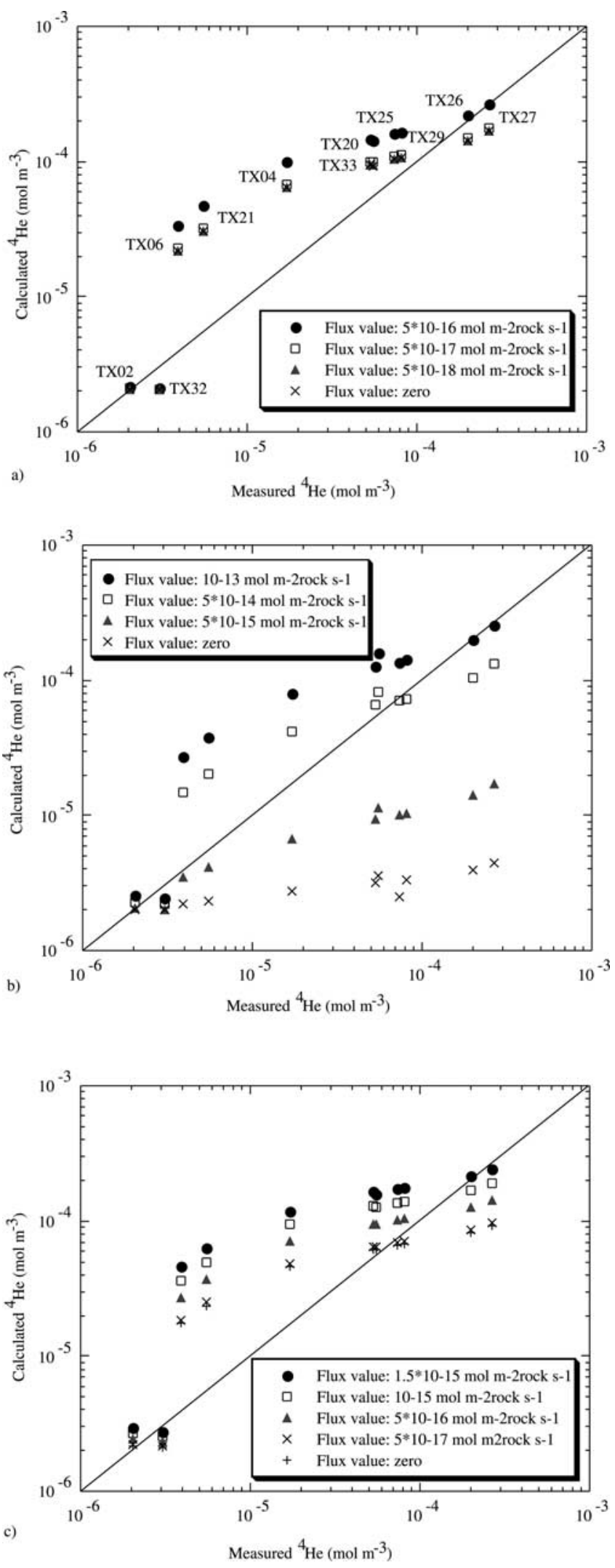

groundwater flow system under conditions corresponding to scenarios 1, 2, and 4 . In this section, arguments concerning the ${ }^{4} \mathrm{He}$ behavior and transport in this system will be presented that support a groundwater flow system as described in Scenario 3, at least for the Carrizo aquifer and Recklaw Formation

\subsubsection{Calibration of ${ }^{4} \mathrm{He}$ Transport Model}

[51] Calibration of the ${ }^{4} \mathrm{He}$ transport model was achieved by prescribing a flux value of $5 \times 10^{-16} \mathrm{~mol}$ $\mathrm{m}_{\text {rock }}^{-2} \mathrm{~s}^{-1}$ (Figures 10a and 10b). Measured and calculated values are similar, with deviations between both values less than $10 \%$ for all samples except sample TX32 and 27, where deviations of -34 and $22 \%$, respectively, are observed. Sample TX32, from the vicinity of the recharge area, displays an unusually high measured concentration relative to other samples at similar distances from the outcrop. We have no definitive explanation for the observed discrepancies at those locations. However, despite simplifications that are obviously introduced in the model as compared to the real situation, the coherency between measured and calculated values is rather satisfactory. A progressive increase of ${ }^{4} \mathrm{He}$ concentration in the Carrizo with increased distance from the outcrop area is clear (see Figure 10a). An interesting feature to note is the vertical distribution of the concentration contour lines for the whole extent of the Carrizo aquifer and in the proximity of the outcrop in the Recklaw Formation. These vertical contour lines exhibit a rapid increase in concentrations with distance (Figure 10a). In contrast, those concentrations are "preserved" over long distances within the Recklaw as the hydraulic conductivity values strongly decrease with distance. Contribution of internal ${ }^{4} \mathrm{He}$ production within the Carrizo in this situation is variable, highest at the proximity of the recharge area with a contribution of around 98\% (sample TX02), lower at the center of the basin with values at around $50 \%$.

[52] Given the geological context of the Carrizo, the ${ }^{4} \mathrm{He}$ external flux value of $5 \times 10^{-16} \mathrm{~mol} \mathrm{~m}_{\text {rock }}^{-2} \mathrm{~s}^{-1}$ found capable of coherently reproducing the ${ }^{4} \mathrm{He}$ concentration distributions in the Carrizo aquifer seems reasonable, even though it is 2 orders of magnitude below the whole terrestrial flux value. As shown by Castro et al. [1998b], ${ }^{4} \mathrm{He}$ flux values strongly decrease toward the surface as a result of progressive dilution exerted by recharge water present in deeper aquifers/formations. As such, this flux is

Figure 9. (opposite) (a) Measured ${ }^{4} \mathrm{He}$ concentrations $\left(\mathrm{mol} \mathrm{m} \mathrm{m}^{-3}\right)$ in the Carrizo aquifer plotted as a function of calculated ones for groundwater flow conditions corresponding to Scenario 1 and for ${ }^{4} \mathrm{He}$ flux values of $5 \times$ $10^{-16}, 5 \times 10^{-17}, 5 \times 10^{-18}$, and zero mol m $\mathrm{m}_{\text {rock }}^{-2} \mathrm{~s}^{-1}$, respectively. (b) Measured ${ }^{4} \mathrm{He}$ concentrations $\left(\mathrm{mol} \mathrm{m}^{-3}\right)$ in the Carrizo aquifer plotted as a function of calculated ones for groundwater flow conditions corresponding to Scenario 2 and for ${ }^{4} \mathrm{He}$ flux values of $10^{-13}, 5 \times 10^{-14}, 5 \times 10^{-15}$, and zero mol m $\mathrm{m}_{\text {rock }}^{-2} \mathrm{~s}^{-1}$, respectively. (c) Measured ${ }^{4} \mathrm{He}$ concentrations $\left(\mathrm{mol} \mathrm{m}^{-3}\right)$ in the Carrizo aquifer plotted as a function of calculated ones for groundwater flow conditions corresponding to Scenario 4 and for ${ }^{4} \mathrm{He}$ flux values of $1.5 \times 10^{-15}, 1 \times 10^{-15}, 5 \times 10^{-16}, 5 \times 10^{-17}$, and zero mol $\mathrm{m}_{\text {rock }}^{-2} \mathrm{~s}^{-1}$, respectively. 
A

a)

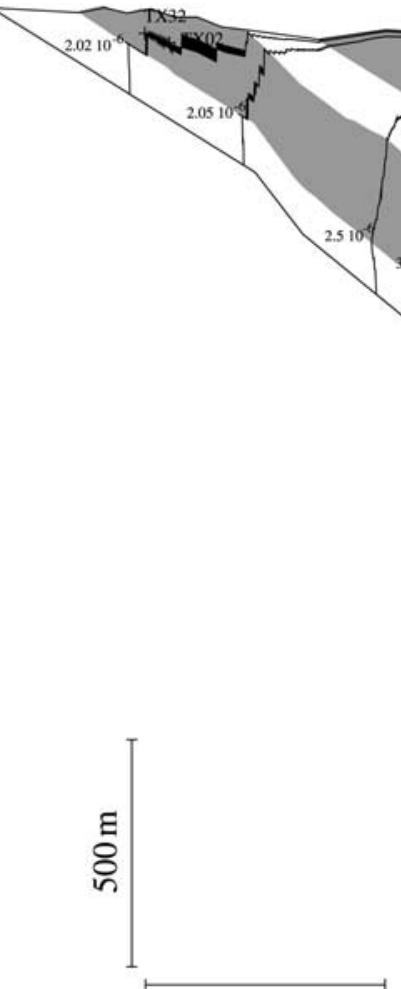

$20 \mathrm{~km}$ b)

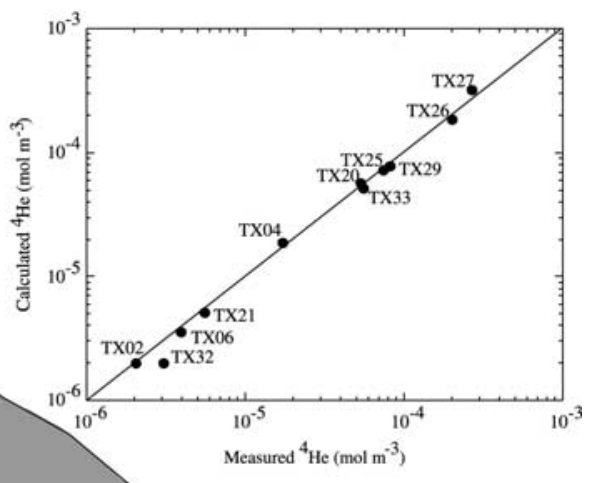

Figure 10. (a) Distribution of ${ }^{4} \mathrm{He}$ concentration contours $\left(\mathrm{mol} \mathrm{m} \mathrm{m}^{-3}\right)$ under flow conditions corresponding to Scenario 3 and a ${ }^{4} \mathrm{He}$ external flux value entering the Carrizo aquifer of $5 \times 10^{-16}$ mol m rock $^{-2} \mathrm{~s}^{-1}$. Contours for values of $10^{-5}$ and $10^{-4} \mathrm{~mol} \mathrm{~m}^{-3}$ are indicated. Except for the indicated contour values of $2.02 \times 10^{-6}, 2.05 \times 10^{-6}, 2.5 \times 10^{-6}, 3 \times 10^{-6}$, and $1.5 \times 10^{-5} \mathrm{~mol} \mathrm{~m}^{-3}$, all other contour values express constant concentration variations of 1 unit inside each order of magnitude. (b) Measured ${ }^{4} \mathrm{He}$ concentrations $\left(\mathrm{mol} \mathrm{m}^{-3}\right)$ for each sample in the Carrizo aquifer plotted as a function of calculated values for same locations and for the situation corresponding to Figure 10a. Line 1:1 is plotted for reference. Well samples are indicated.

not representative of the entire ${ }^{4} \mathrm{He}$ crustal flux but instead represents simply a flux entering a particular aquifer, in this case the Carrizo. Until proved wrong (as discussed by Konikow and Bredehoeft [1992]), the present groundwater flow model corresponding to Scenario 3 which is validated by a coherent ${ }^{4} \mathrm{He}$ transport model seems to indicate that a very simple analytical model is inadequate to reproduce groundwater flow conditions and ${ }^{4} \mathrm{He}$ transport in this type of system. Indeed, the flux value used for calibration of this transport model is 1 order of magnitude lower as compared to that one found by Castro et al. [2000], which was based on an average velocity value of $1.6 \mathrm{~m} \mathrm{yr}^{-1}$ [cf. Pearson and White, 1967; Brinkman, 1981]. Groundwater flow simulations presented here seem to indicate that the use of an average velocity value for the entire aquifer is rather a too simplistic approach and inadequate to reproduce the velocity field in place in the area.

[53] Sensitivity tests on different flux values were conducted. For example, a prescribed flux value of $5 \times 10^{-15}$ mol $\mathrm{m}_{\text {rock }}^{-2} \mathrm{~s}^{-1}$ is extremely high, with calculated values up to 6 times the measured ones. Calculated concentrations for a lower flux value of $5 \times 10^{-17} \mathrm{~mol} \mathrm{~m}_{\text {rock }}^{-2} \mathrm{~s}^{-1}$ display values up to $40 \%$ below the measured ones. With lower flux values, deviations between measured and calculated concentrations become smoother as contribution of in situ production increases.

\subsubsection{Time Needed for Equilibration of ${ }^{4} \mathrm{He}$ in Transient Conditions}

[54] Tests were made to ascertain that steady state for ${ }^{4} \mathrm{He}$ transport had been established within a reasonable period of time while taking into account the geological depositional history of the system. Transient simulations were done with time steps of 100,000 years assuming a steady state flow regime. All prescribed parameters remained the same. An initial condition of zero ${ }^{4} \mathrm{He}$ concentration was imposed. Results show that transport of ${ }^{4} \mathrm{He}$ in steady state was reached in approximately 1 Myr. Taking into account that the youngest formation being simulated, the Queen City, is about 47 Myr old and the entire sedimentary system in place in the area with the exception of Quaternary deposits are 
about 35 Myr old, steady state was reached within a reasonable period of time and is compatible with the depositional history in the area.

\subsubsection{Impact of Aquitard Hydraulic Conductivity Values on ${ }^{4} \mathrm{He}$ Concentrations}

[55] Although the Recklaw Formation is mostly regarded as a confining layer, calibration of the groundwater flow model for Scenario 3 was achieved by prescribing a gradual decrease of hydraulic conductivity in this formation, with an initial relatively high value of $3 \times 10^{-8} \mathrm{~m} \mathrm{~s}^{-1}$, down to $6 \times$ $10^{-12} \mathrm{~m} \mathrm{~s}^{-1}$ at the very end of the cross section. The question arises as to whether or not hydraulic conductivities in this formation significantly impact the distribution of ${ }^{4} \mathrm{He}$ concentrations in the Carrizo. In order to address this question, sensitivity tests on this parameter were carried out within the Recklaw. All other parameters remained unchanged. Figures 11a, 11b, 11c and 11d show the distribution of ${ }^{4} \mathrm{He}$ concentrations in the system for initial hydraulic conductivity values 1 and 2 orders of magnitude lower as compared to the calibrated groundwater flow model. The same decrease factor was applied. Results show clearly a strong increase of ${ }^{4} \mathrm{He}$ concentrations within the Carrizo, up to 2.6 times in the first case, up to 16 times in the later, for lower initial hydraulic conductivity values of $3 \times 10^{-9}$ and $3 \times 10^{-10} \mathrm{~m} \mathrm{~s}^{-1}$, respectively. By strongly reducing the hydraulic conductivity of the overlying confining layer, a strong decrease of upward water movement (vertical leakage rate) prevents ${ }^{4} \mathrm{He}$ from leaving the Carrizo by advection at a reasonable rate, thus leading to an excessive accumulation of ${ }^{4} \mathrm{He}$ in the system. For an initial hydraulic conductivity value of $3 \times 10^{-10} \mathrm{~m} \mathrm{~s}^{-1}$, extremely strong ${ }^{4} \mathrm{He}$ concentration gradients are observed within the Recklaw (see Figure 11c), indicating that ${ }^{4} \mathrm{He}$ is exiting the system through this formation, but possibly mostly by diffusion, and at a much lower rate as compared to a situation where significant advective transport is occurring. Variations of hydraulic conductivity values in the Recklaw, such as the ones here achieved for the calibrated groundwater flow model corresponding to Scenario 3, are consistent with geological information present in the area. These results highlight the potential contribution of a tracer such as ${ }^{4} \mathrm{He}$ for deciphering at least the order of magnitude of low hydraulic conductivity values present in confining layers.

\subsubsection{Water Age Distribution}

[56] Earlier in this paper we indicated that one of our main concerns is to ascertain that a calibrated groundwater flow model is indeed representative of the real groundwater flow system before artificial stresses were induced. Only then, and as previously mentioned, the establishment of a direct correspondence between noble gas temperatures and groundwater ages will be possible, so that the reconstruction of past climate can be made. Although we cannot yet demonstrate unequivocally that the groundwater flow system corresponding to Scenario 3 is indeed representative of the real one, and additional constraints will be imposed in the future, arguments and results presented here suggest that this scenario represents a much closer reproduction of the actual system compared to the other scenarios presented.

[57] From Scenario 3 presently validated by ${ }^{4} \mathrm{He}$, we have determined the distribution of advective water ages (Figure 12). A clear increase in water ages within the Carrizo is observed, with very young ages $(<10,000$ years $)$ in the initial part of the cross section, followed by a strong progressive increase in ages with increased recharge distance. This increase becomes greater with increased distance and is represented by the transition zone going from greenish toward reddish colors, where ages are equal or greater than 1 Myr. In the Recklaw, the presence of older ages at shorter distances from the outcrop as compared to the Carrizo aquifer are due to the lower hydraulic conductivity (and therefore velocity) values imposed in this formation. Another interesting feature to note is the presence of old waters (in green) at the base of the Queen City Aquifer in the second half of the cross section, which results from the upward water movement in the Recklaw, carrying older waters to the above aquifer. These water ages become progressively younger toward the top of the formation (blue areas). Owing to the very low hydraulic conductivity values prescribed to the Wilcox, water ages there are extremely old, as seen in the red color. Note that calculated advective water ages in the Carrizo Aquifer for groundwater flow Scenario 3 are not significantly different from calculated ${ }^{14} \mathrm{C}$ ages for samples where the percentage of modern carbon is above detection limit [cf. Castro et al., 2000].

\section{Summary and Conclusions}

[58] This paper highlights statements made by Konikow and Bredehoeft [1992], Maloszewski and Zuber [1993], and others on the nonuniqueness of groundwater flow models and the impossibility of fully validating such models.

[59] Through a set of groundwater flow simulations in the Carrizo aquifer and adjacent formations in Atascosa and McMullen Counties, Texas, four calibrated very different groundwater flow scenarios on hydraulic head values are presented. Calibration for all models was achieved through a different combination of prescribed hydraulic conductivities in those formations, with a primary focus on the Carrizo and overlying confining layer, the Recklaw Formation. It is shown that all calibrated groundwater flow models lead to a possible, not unreasonable scenario for the area concerning recharge rates for all formations, water velocity field, and computed water ages. Thus no criteria were available for the independent exclusion or invalidation of any of the possible scenarios. This set of simulations highlights that a high number of solutions can be found in an almost-trivial approach. It is shown that minimal deviations on all calculated hydraulic heads (maximum deviation of 3.3\%) correspond to assigned hydraulic conductivity values in the Carrizo and overlying confining layer varying up to 2 orders of magnitude in certain areas. Thus this study provides some answers concerning the degree of freedom available in the calibration of such models.

[60] Attempts at calibrating the ${ }^{4} \mathrm{He}$ concentration distribution in the Carrizo by imposing different ${ }^{4} \mathrm{He}$ external flux values entering the base of the Carrizo aquifer were also undertaken. Those attempts failed for all calibrated groundwater flow models except one. Thus one calibrated groundwater flow model has been validated by ${ }^{4} \mathrm{He}$. This model shows exponential decreases of hydraulic conductivity values within both the Carrizo Aquifer and Recklaw Formation. These values vary, for the Carrizo, between $5 \times 10^{-4}$ and $4 \times 10^{-8} \mathrm{~m} \mathrm{~s}^{-1}$ from the outcrop to the discharge area, respectively. For the Recklaw Formation, 
A

a)

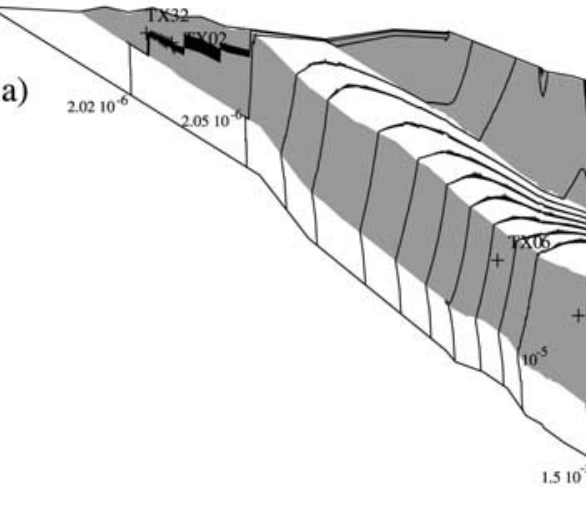

c)

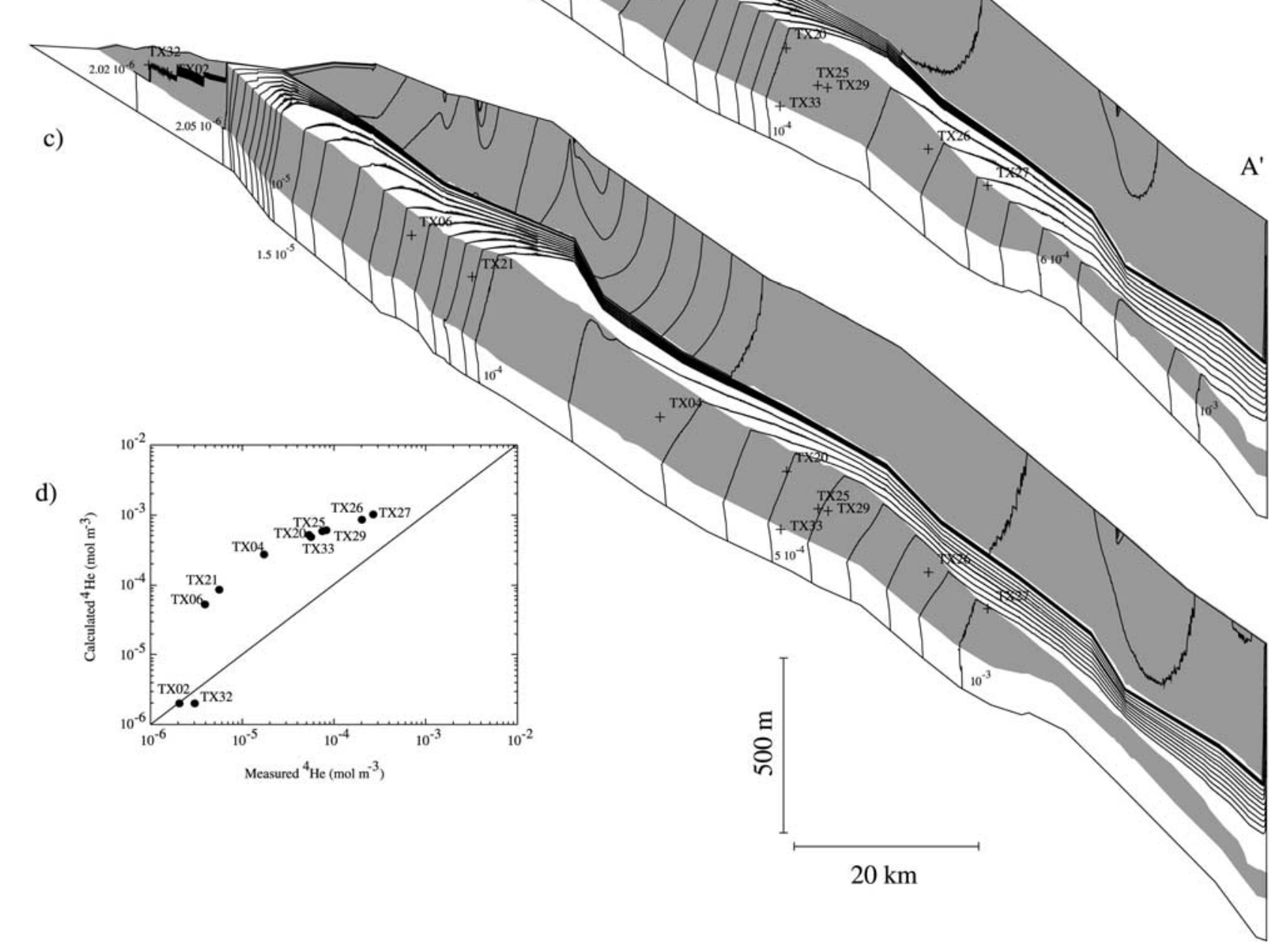

b)

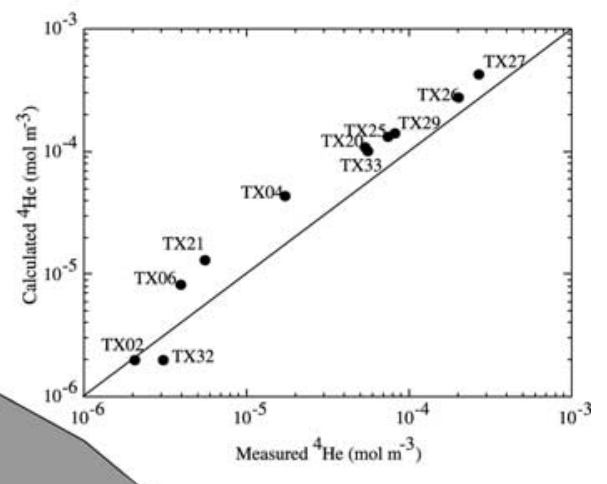

Figure 11. (a) Distribution of ${ }^{4} \mathrm{He}$ concentration contours $\left(\mathrm{mol} \mathrm{m} \mathrm{m}^{-3}\right)$ under flow conditions corresponding to Scenario 3. All parameters are the same as those of Figure 10, except for the hydraulic conductivity value within the Recklaw, which is here 1 order of magnitude lower in the outcrop area $(3 \times$ $10^{-9} \mathrm{~m} \mathrm{~s}^{-1}$ ). The decrease factor prescribed remains the same. (b) Measured ${ }^{4} \mathrm{He}$ concentrations $\left(\mathrm{mol} \mathrm{m}^{-3}\right)$ for each sample in the Carrizo aquifer plotted as a function of calculated values for same locations and for situation corresponding to Figure 11a. Line 1:1 is plotted for reference. Well samples are indicated. (c) Same as described in Figure 11a, except that the initial hydraulic conductivity value for the Recklaw Formation is here 2 orders of magnitude lower as compared to Figure 10 a, i.e., $3 \times 10^{-10} \mathrm{~m} \mathrm{~s}^{-1}$. (d) Measured ${ }^{4} \mathrm{He}$ concentrations $\left(\mathrm{mol} \mathrm{m}^{-3}\right.$ ) for each sample in the Carrizo aquifer plotted as a function of calculated values for the same locations and for situation corresponding to Figure 11c. 


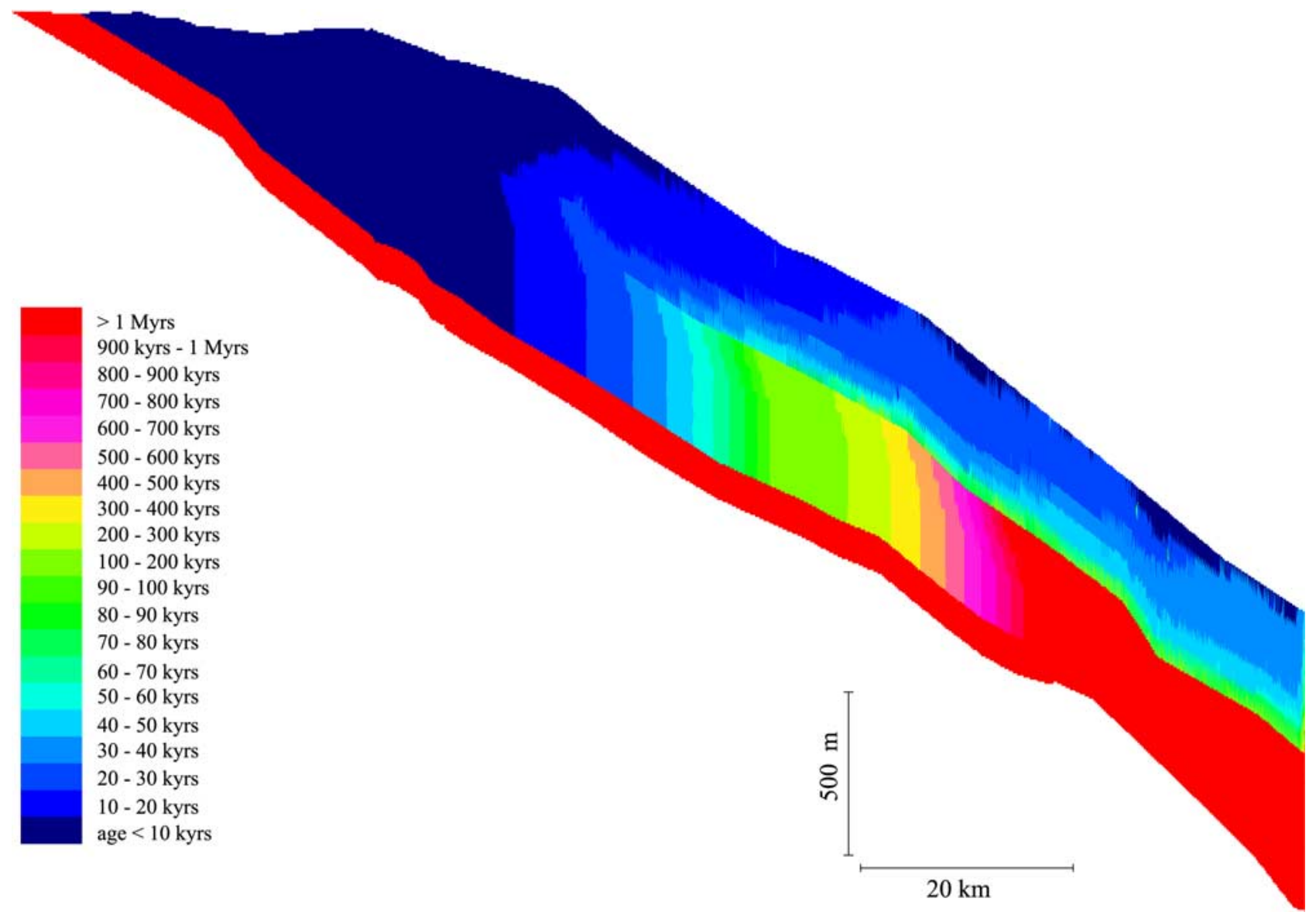

Figure 12. Distribution of calculated advective water ages (thousands of years) in the system. Water age contours correspond to constant variations of 10,000 years between 0 and 0.1 Myr and variations of 100,000 years for time periods varying between 0.1 and $1 \mathrm{Myr}$, each one of these intervals being represented by a different color, from the youngest (dark blue) to the oldest (red), which corresponds to ages higher than 1 Myr.

correspondent values are $3 \times 10^{-8}$ and $6 \times 10^{-12} \mathrm{~m} \mathrm{~s}^{-1}$, respectively. The ${ }^{4} \mathrm{He}$ external flux value for which calibration of the transport model was achieved is $5 \times$ $10^{-16} \mathrm{~mol} \mathrm{~m}_{\text {rock }}^{-2} \mathrm{~s}^{-1}$. This study indicates the presence of a ${ }^{4} \mathrm{He}$ external flux 1 order of magnitude lower as compared to that one found by Castro et al. [2000], possibly indicating that a very simple analytical model is inadequate for reproducing groundwater flow conditions and ${ }^{4} \mathrm{He}$ transport in this type of system.

[61] The effect of low hydraulic conductivity values present in confining layers on ${ }^{4} \mathrm{He}$ concentrations and its potential contribution for deciphering at least the order of magnitude of this parameter within these formations is also shown.

[62] Although three of the groundwater flow models were inadequate at reproducing a coherent picture concerning this isotope's behavior, all calibrated models revealed, without exception, the presence of a number of common clear patterns on the regional groundwater flow system in the area. Among those are the following: (1) an essentially horizontal flow occurring in the Carrizo aquifer; (2) vertical leakage occurring over the entire extent of the Recklaw; and (3) presence of indirect recharge of the Recklaw Formation through the Carrizo aquifer. By formulating several scenarios of groundwater flow, consider- able knowledge about groundwater processes is gained through selective model invalidation. The potential of employing an independent tracer such as ${ }^{4} \mathrm{He}$ for reducing the nonuniqueness problem of groundwater flow models is simultaneously highlighted.

[63] Acknowledgments. The authors wish to thank two anonymous reviewers as well as K. C. Lohmann and B. H. Wilkinson for their insightful and constructive comments for improving the manuscript. We also thank O. Stab for making available to us the Delos code and E. Baker (USGS, Austin) for his help in providing additional geological/structural information used for construction of the model. Financial support by the Horace H. Rackham School of Graduate Studies at the University of Michigan (grant G002183) is greatly appreciated.

\section{References}

Alexander, W. H., and D. E. White, Groundwater resources of Atascosa and Frio Counties, Texas, Rep. 32, 211 pp., Tex. Water Dev. Board, Austin, Tex., 1966.

Allegre, C. J., T. Staudacher, and P. Sarda, Rare gas systematics: Formation of the atmosphere, evolution and structure of the Earth's mantle, Earth Planet. Sci. Lett., 81, 127-150, 1986.

Alley, W. M., and P. A. Emery, Groundwater model of the blue river basin, Nebraska-Twenty years later, J. Hydrol., 85, 225-249, 1986.

Andrews, J. N., The isotopic composition of radiogenic helium and its use to study groundwater movement in confined aquifers, Chem. Geol., 49 , $339-351,1985$

Ballentine, C. J., R. K. O’Nions, E. R. Oxburg, F. Horvath, and J. Deak, Rare gas constraints on hydrocarbon accumulation, crustal degassing and 
groundwater flow in the Pannonian Basin, Earth Planet. Sci. Lett., 105 $229-246,1991$.

Banton, O., G. Porel, and F. Delay, Coupling of the time domain random walk method with the finite fragment method to simulate flow and transport in 1-D heterogenous media, J. Hydrol., 201(1-4), 49-61, 1997.

Bebout, D. G., V. J. Gavenda, and A. R. Gregory, Geothermal resources, Wilcox Group, Texas Gulf Coast, 82 pp., Bur. of Econ. Geol., Univ. of Tex. at Austin, 1978.

Beven, K., Changing ideas in hydrology-The case of physically based models, J. Hydrol., 105, 157-172, 1989.

Bredehoeft, J. D., Microcomputer codes for simulating transient groundwater flow in two and three space dimensions, U.S. Geol. Surv. Open File Rep., 90-559, 73 pp., 1990.

Bredehoeft, J. D., and G. F. Pinder, Mass transport in flowing groundwater, Water Resour. Res., 9(1), 194-210, 1973.

Bredehoeft, J. D., C. E. Neuzil, and P. C. D. Milley, Regional flow in the Dakota Aquifer: A study of the role of confining layers, U.S. Geol. Surv. Water Supply Pap., 2237, 1-45, 1983.

Brinkman, J. E., Water age dating of Carrizo sand, Ph.D. dissertation, 131 pp., Univ. of Ariz., Tucson, 1981.

Burrus, J., Overpressure models for clastic rocks, their relation to hydrocarbon expulsion: A critical reevaluation, Am. Assoc. Pet. Geol. Mem., 70, 35-63, 1998

Carrera, J., and S. P. Neuman, Estimation of aquifer parameters under transient and steady state conditions: 1 . Maximum likelihood method incorporating prior information, Water Resour. Res., 22(2), 199-210, 1986a.

Carrera, J., and S. P. Neuman, Estimation of aquifer parameters under transient and steady state conditions: 2 . Uniqueness, stability, and solution algorithms, Water Resour. Res., 22(2), 211-227, 1986b.

Castro, M. C., A. Jambon, G. de Marsily, and P. Schlosser, Noble gases as natural tracers of water circulation in the Paris Basin: 1. Measurements and discussion of their origin and mechanisms of vertical transport in the basin, Water Resour. Res., 34(10), 2443-2466, 1998a.

Castro, M. C., P. Goblet, E. Ledoux, S. Violette, and G. de Marsily, Noble gases as natural tracers of water circulation in the Paris Basin: 2. Calibration of a groundwater flow model using noble gas isotope data, Water Resour. Res., 34(10), 2467-2483, 1998b.

Castro, M. C., M. Stute, and P. Schlosser, Comparison of ${ }^{4} \mathrm{He}$ and ${ }^{14} \mathrm{C}$ ages in simple aquifer systems: Implications for groundwater flow and chronologies, Appl. Geochem., 15, 1137-1167, 2000

Cooley, R. L., Incorporation of prior information on parameters into nonlinear regression groundwater flow models: 2. Applications, Water Resour. Res., 19(3), 662-676, 1983.

Craig, H., J. E. Lupton, and Y. Horribe, A mantle helium component in circum-Pacific volcanic gases: Hakone, the Marianas, and Mt. Lassen, in Terrestrial Rare Gases, edited by E. C. Alexander Jr. and M. Ozima, pp. 3-16, Jpn. Sci. Soc. Press, Tokyo, 1978.

de Marsily, G., Quantitative Hydrogeology, 440 pp., Academic, San Diego, Calif., 1986.

de Marsily, G., P. Combes, and P. Goblet, Comment on "Groundwater models cannot be validated" by L. F. Konikow and J. D. Bredehoeft, Adv. Water Resour, 15, 367-369, 1992.

Domenico, P. A., and F. W. Schwartz, Physical and Chemical Hydrogeology, 2nd ed., 506 pp., John Wiley, New York, 1998.

Fisher, W. L., Gulf Coast Basin tertiary delta systems, in Delta Systems in the Exploration for Oil and Gas, edited by W. L. Fisher et al., pp. 3-90, Bur. of Econ. Geol., Univ. of Tex. at Austin, 1969.

Fisher, W. L., Depositional systems of the Carrizo-Upper Wilcox of Texas and their relationship to the occurrence of oil and gas, Corpus Christ Geol. Soc. Bull., 13(4), 1-3, 1972.

Fogg, G. E., S. J. Seni, and C. W. Kreitler, Three-dimensional groundwater modeling in depositional systems, Wilcox Group, Oakwood salt dome area, East Texas, Rep. of Invest. 133, 55 pp., Bur. of Econ. Geol., Univ. of Tex. at Austin, 1983.

Goblet, P., Modélisation des transferts de masse et d'énergie en aquifère, Ph.D. dissertation, 199 pp., Univ. of Paris VI, Paris, France, 1980.

Goblet, P., Programme METIS: Simulation d'écoulement et de transport miscible en milieu fracturé, notice de conception au 9 Février, Rapp. CIG-ENSMP, LHM/RD/89/23, 120 pp., Ecole Nationale Supérieure des Mines de Paris, Paris, 1989.

Goblet, P., Programme METIS: Simulation d'écoulement et de transport miscible en milieu poreux et fracture, notice de conception, Mise à jour au 1er/11/99, Rapp. CIG/LHM/RD/99/38, Ecole Nationale Supérieure des Mines de Paris, Paris, 1999

Hamlin, H. S., Depositional and groundwater flow systems of the CarrizoUpper Wilcox, South Texas, Rep. of Invest. 175, 61 pp., Bur. of Econ. Geol., Univ. of Tex. at Austin, 1988.
Harris, H. B., Groundwater resources of LaSalle and McMullen Counties, Texas, Tex. Water Dev. Board Bull., 6520, 59 pp., 1965.

Harvey, C. F., and S. M. Gorelick, Mapping hydraulic conductivity: Sequential conditioning with measurements of solute arrival time, hydraulic head, and local conductivity, Water Resour. Res., 31(7), 1615-1626, 1995.

Honda, M., I. MacDougall, D. B. Patterson, A. Doulgeris, and D. A. Clague, Possible solar noble-gas component in Hawaiian basalts, Nature, 349, 149-151, 1991

Klemt, W. B., G. L. Duffin, and G. R. Elder, Groundwater resources of the Carrizo aquifer in the Winter Garden area of Texas, Tex. Water Dev. Board Rep., 210(1), 30 pp., 1976.

Konikow, L. F., and J. D. Bredehoeft, Computer model of two-dimensional solute transport and dispersion in ground water, U.S. Geol. Surv. Tech Water Resour. Invest., Book 7, chap. C2, 90 pp., 1978.

Konikow, L. F., and J. D. Bredehoeft, Groundwater models cannot be validated, Adv. Water Resour., 15, 75-83, 1992.

LBG-Guyton Associates, Interaction between ground water and surface water in the Carrizo-Wilcox Aquifer, Rep. W600.8 C235, Tex. Water Dev. Board, Univ. of Tex. at Austin, 1998.

Ledoux, E., Modeles mathematiques en hydrogeologie, Rapp. CIG, LHM/ $R D / 86 / 12,120$ pp., Ecole Nationale Superieure des Mines de Paris, 1986.

Lupton, J. E., Terrestrial inert gases: Isotope tracer studies and clues to primordial components in the mantle, Annu. Rev. Earth Planet. Sci., $111,371-414,1983$

Maloszewski, P., and A. Zuber, Principles and practice of calibration and validation of mathematical models for the interpretation of environmental tracer data in aquifers, Adv. Water Resour., 16, 173-190, 1993.

Marcantonio, F., S. Higgins, R. F. Anderson, M. Stute, P. Schlosser, and E. T. Rasbury, Terrigenous helium in deep-sea sediments, Geochim. Cosmochim. Acta, 62, 1535-1543, 1998.

Marquardt, G., and E. Rodriguez, Groundwater resources of the Carrizo Aquifer in the Winter Garden area of Texas, Tex. Water Dev. Board Rep., 210(2), 466 pp., 1977.

Martel, D. J., J. Deak, P. Dovenyi, F. Horvath, R. K. O'Nions, E. R. Oxburgh, L. Stegena, and M. Stute, Leakage of helium from the Pannonian Basin, Nature, 342, 908-912, 1989.

Mason, C. C., Geology and groundwater resources, Dimmit County, Texas, Tex. Board Water Eng. Bull., 6003, 234 pp., 1960

McLaughlin, D., and L. R. Townley, A reassessment of the groundwater inverse problem, Water Resour. Res., 32(5), 1131-1161, 1996.

Murray, G. E., Midway Stage, Sabine Stage, and Wilcox Group, Am. Assoc. Pet. Geol. Bull., 39, 671-689, 1955.

Ohsumi, T., and Y. Horibe, Diffusivity of $\mathrm{He}$ and $\mathrm{Ar}$ in deep-sea sediments, Earth Planet. Sci. Lett., 70, 61-68, 1984.

O'Nions, R. K., and E. R. Oxburgh, Heat and helium in the Earth, Nature, 306, 429-431, 1983.

Parker, R. L., Composition of the Earth's crust, in Data of Geochemistry, 6th ed., chap. D, U.S. Geol. Surv. Prof. Pap., USGS-0440-D, 1-19, 1967.

Payne, J. N., Significance of lithofacies of the Cane River Formation or equivalents of Arkansas, Louisiana, Mississippi, and Texas, U.S. Geol. Surv. Prof. Pap., 569-D, 11 pp., 1972.

Payne, J. N., Geohydrologic significance of lithofacies of the Carrizo Sand of Arkansas, Louisiana, and Texas and the Meridian sand of Mississipi, U.S. Geol. Surv. Prof. Pap., 569-C, 11 pp., 1975.

Pearson, F. J., Jr., Groundwater ages and flow rates by the carbon 14 method, Ph.D. dissertation, Univ. of Tex. at Austin, 1966.

Pearson, F. J., Jr., and D. E. White, Carbon-14 ages and flow rates of water in Carrizo Sand, Atascosa County, Texas, Water Resour. Res., 3, 251261, 1967.

Plummer, F. B., Cenozoic systems in Texas, in The Geology of Texas, vol. 1, Stratigraphy, edited by E. H. Sellars, W. C. Adkins, and F. B. Plummer, Bull. 3232, pp. 519-818, Univ. of Tex. at Austin, 1932.

Prickett, T. A., T. C. Naymik, and C. G. Lonnquist, A random-walk solute transport model for selected groundwater quality evaluations, Bull. Ill. 65, 103 pp., State Water Surv., Champaign, Ill., 1981.

Solomon, D. K., A. Hunt, and R. J. Poreda, Source of radiogenic helium 4 in shallow aquifers: Implications for dating groundwater, Water Resour. Res., 32(6), 1805-1813, 1996.

Stab, O., La Librairie Delos, notice de conception Sept 1995, Rapport technique de l'Ecole des Mines de Paris/CGES, 1995.

Steiger, R. H., and E. Jager, Subcomission on geochronology: Convention on the use of decay constant in gas and cosmochronology, Earth Planet. Sci. Lett., 36, 359-362, 1977.

Stute, M., C. Sonntag, J. Deak, and P. Schlosser, Helium in deep circulating groundwater in the Great Hungarian Plain: Flow dynamics and crustal and mantle helium fluxes, Geochim. Cosmochim. Acta, 56, 2051-2067, 1992. 
Sun, N. Z., and W. W. G. Yeh, A stochastic inverse solution for transient groundwater flow: Parameter identification and reliability analysis, Water Resour. Res., 28(12), 3269-3280, 1992.

Torgersen, T., Controls on pore-fluid concentration of ${ }^{4} \mathrm{He}$ and ${ }^{222} \mathrm{Rn}$ and the calculation of ${ }^{4} \mathrm{He} /{ }^{22} \mathrm{Rn}$ ages, J. Geochem. Explor., 13, 57-75, 1980.

Torgersen, T., and W. B. Clarke, Helium accumulation in groundwater, I, An evaluation of sources and the continental flux of crustal ${ }^{4} \mathrm{He}$ in the Great Artesian Basin, Australia, Geochim. Cosmochim Acta, 49, 1211$1218,1985$.

Toth, J., A theory of groundwater motion in small drainage basins in central Alberta, Canada, J. Geophys. Res., 67(11), 4735-4812, 1962.

Townley, L. R., and J. L. Wilson, Computationally efficient algorithms for parameter estimation and uncertainty propagation in numerical models of groundwater flow, Water Resour. Res., 21(2), 1851-1860, 1985.

Trescott, P. C., Documentation of finite-difference model for simulation of three-dimensional ground-water flow, U.S. Geol. Surv. Open File Rep., 75-438, 32 pp., 1975.
Weiss, R. F., The solubility of nitrogen, oxygen and argon in water and seawater, Deep Sea Res., 17, 721-735, 1970.

Weiss, R. F., Solubility of helium and neon in water and seawater, J. Chem. Eng. Data, 16, 235-241, 1971.

Zimmerman, D. A., et al., A comparison of seven geostatistically based inverse approaches to estimate transmissivities for modeling advective transport by groundwater flow, Water Resour. Res., 34(6), 1373-1413, 1998.

M. C. Castro, Department of Geological Sciences, University of Michigan, 2534 C. C. Little Building, Ann Arbor, MI 48109-1063, USA. (mccastro@umich.edu)

P. Goblet, Centre d'Informatique Géologique, Ecole des Mines de Paris, UMR 7619 Sisyphe, 77305 Fontainebleau, France. 